\title{
Caenorhabditis elegans as a model organism in obesity research
}

\author{
Aneta Agnieszka Dyczkowska, Agnieszka Chabowska-Kita* \\ Institute of Bioorganic Chemistry Polish Academy of Science, Poznań, Poland
}

\begin{abstract}
Obesity is a global health problem associated with many comorbidities such as type 2 diabetes and cancer. The number of individuals with overweight and obesity have increased dramatically within the past few years. Given the worldwide cost of an obesity pandemic, it is crucial to understand molecular pathways and identify novel factors that regulate fat storage in humans. In recent years, Caenorhabditis elegans has been widely used to investigate metabolic and neuroendocrine mechanisms involved in the regulation of energy metabolism. In this review, we describe similarities in fundamental signalling pathways regulating fat accumulation between nematodes and mammals. Like in humans, fat storage in $C$. elegans depends on the interaction of genetic and environmental factors such as diet, microbiota and ambient temperature. Despite many challenges, the simplicity of use, relatively short lifespan, genetic conservation and availability of many valuable experimental techniques make $C$. elegans an attractive and useful model organism in obesity research.
\end{abstract}

Key words: obesity, Caenorhabditis elegans, microbiota, dietary restriction, bioactive compounds, temperature

\section{Introduction}

Obesity is a global health problem that affects virtually all socioeconomic groups independent of age and country. Overweight and obesity, defined as abnormal or excessive fat accumulation, develop as a result of a longtermimbalance between energy consumption and energy expenditure. Global increase in the intake of energydense food and physical inactivity due to sedentary lifestyle, increasing transportation and urbanisation have led to a dramatic rise in the number of individuals with obesity worldwide (World Health Organization, (WHO)). The number of adult women (over 20 years) with obesity increased from 69 to 390 million, whereas the number of adult men increased from 31 million to 281 million between 1975 and 2016. Moreover, the prevalence of childhood and adolescent obesity (5-19 years) increased from 5 million to 50 million for girls and from 6 million to 74 million for boys between 1975 and 2016 (AbarcaGómez et al., 2017).

Energy homeostasis requires coordinated action of multiple signalling pathways that regulate food sensation, eating behaviour, nutrient uptake, fat storage and energy expenditure (Pang et al., 2014). Disruption of any of these pathways may lead to an energy imbalance, which can cause obesity and other metabolic diseases (WHO, 1998; Willett et al., 1999). The early-onset monogenic forms of obesity in humans are relatively rare and include mutations in genes of the leptin-melanocortin pathway, leading to abnormal feeding behaviour and endocrine disorders. In most cases, genetically inherited obesity develops because of an accumulation of mutations in multiple genetic loci. The analysis of genomewide scans demonstrated over 250 human obesity quantitative trait loci (QTLs) (Rankinen et al., 2006). Although the development of obesity depends on both genetic and environmental causes, multiple genes seem to increase the risk of weight gain through interaction with environmental factors, e.g. unhealthy food, sedentary lifestyle and medication use. People with obesity are at a much higher risk for the development of serious medical conditions such as high blood pressure, heart attack, stroke, type 2 diabetes (T2D), gallbladder disease and different types of cancer (Haase et al., 2021).

Development of new experimental strategies that could prevent and/or treat obesity and its comorbidities demand deeper understanding of molecular mechanisms

\footnotetext{
* Corresponding author: Institute of Bioorganic Chemistry Polish Academy of Science, Poznań, Poland; e-mail: akita@ibch.poznan.pl
} 
that regulate fat accumulation. Although rodents are the most commonly used animal models in obesity studies, modern scientific research aims to reduce the need for vertebrates or partially replace them with ethically more acceptable lower model organisms. Many researchers aim to study obesity-related metabolism by using invertebrates including Caenorhabditis elegans, which has been used in research for over 50 years. Caenorhabditis elegans is the first eukaryotic multicellular organism with a complete genome sequenced (The $C$. elegans Sequencing Consortium, 1998) and the cell lineage of each cell type mapped (Sulston and Horvitz, 1977; Sulston and Schierenberg et al., 1983). At least $60-80 \%$ of human genes are conserved in C. elegans, and many of them were shown to be associated with human diseases (Sonnhammer and Durbin, 1997; Lai et al., 2000). Genetic conservation, transparent body, and relatively short lifespan have established $C$. elegans as a highly attractive animal model to study gene functions in various human diseases, including metabolic disorders. Many nematode genes involved in the regulation of lipid metabolism, e.g. fatty acid (FA) synthesis, elongation, desaturation and $\beta$-oxidation as well as neuropeptide, serotonergic and insulin/IGF-1 signalling (IIS) pathways, have their orthologs in humans, indicating that basic mechanisms controlling energy homeostasis might be conserved in C. elegans (Chiang and MacDougald, 2003; Mullaney and Ashrafi, 2009). Throughout this review, we provide evidence that $C$. elegans is an animal model with a high potential to study genetic and environmental origins of obesity. We summarise basic principles and signalling pathways regulating fat storage in $C$. elegans. We also describe several genetic factors that regulate fat accumulation and outline metabolic effects associated with environmental changes, e.g. type of diet, microbiota, dietary restriction (DR) and temperature, in nematodes and mammals. We focus on the similarities between factors and signalling pathways regulating fat storage in nematodes and humans and emphasise the usefulness of $C$. elegans as a model in obesity research.

\section{Fat storage in $C$. elegans}

Pathways regulating fat storage, e.g. insulin, transforming growth factor- $\beta$ (TGF- $\beta$ ), serotonin/5-hydroxytryptamine (5-HT) and mammalian target of rapamycin (mTOR) signalling pathways (Greer et at., 2008; Srini- vasan et al., 2008; Soukas et al., 2009) as well as factors modulating synthesis, elongation, desaturation and degradation of FAs (Watts and Browse, 2002; Van Gilst et al., 2005; Yang et al., 2006), seem to be conserved among nematodes and humans (Watts and Browse, 2002). Because $C$. elegans do not have dedicated adipose tissue (AT), fat is accumulated in lipid droplets (LDs), which are ubiquitous fat storage organelles localised mainly in the intestine (O'Rourke et al., 2009). LDs are surrounded by a phospholipid monolayer composed of phosphatidylcholine and phosphatidylethanolamine and contain neutral lipids such as triglycerides (TAGs) and cholesterol esters (CEs) (Tauchi-Sato et al., 2002). LDs are located in close proximity to the endoplasmic reticulum (ER), which produces precursors of TAGs, including diglycerides (DAGs), which are converted to TAGs by diacylglycerol O-acyltransferase 2 (DGAT-2) at the ER-LD interface (Cao et al., 2019). Proteins of the seipin/BSCL2 type (SEIP-1) play a conserved role in humans and nematodes and promote LD biogenesis (Cao et al., 2019). Seipins are present at ER-LD junctions where they might be responsible for the proper partitioning of lipids and proteins between the ER and LDs (Cao et al., 2019).

In humans, FAs are provided through absorbed nutrients or via the gut microbiota (White, 2009; Jones et al., 2011). In C. elegans, FAs needed for TAG synthesis are obtained from a bacterial diet or synthesised de novo from acetyl CoA. In the de novo TAG synthesis, acetyl $\mathrm{CoA}$ is converted by acetyl CoA carboxylase (ACC) and FA synthase (FAS) into palmitic acid $(16: 0)$, which can then be converted to TAGs, phospholipids (PLs) or other long-chain polyunsaturated FAs (PUFAs). FA-modifying enzymes such as desaturases delta-5 (FAT-4) and delta-6 (FAT-3) as well as PUFA elongase (ELO-1) found in nematodes are very similar to their mammalian counterparts (Watts and Browse, 2002; Wallis et al., 2002). Worms convert excess nutrients into TAGs through the up-regulation of dgat-2, which is involved in TAG synthesis, and vitellogenin 2 (vit-2), which is responsible for the transport of dietary lipids into LDs, thus promoting fat accumulation (Wang et al., 2020).

LDs play an essential role in the regulation of energy metabolism, membrane expansion during cell division and intracellular fat storage (Wilfling et al., 2013). Similarities in the composition and structure of LDs indicate their evolutionary conservation from worms to humans 
(Vrablik et al., 2015; Mak, 2011). Studies in rodents indicate that IIS plays a crucial role in the regulation of AT morphology (Lee et al., 2016), and impaired AT plasticity is associated with insulin resistance (Kim et al., 2014). Hypertrophy of LDs is linked to increased plasma insulin levels in individuals with obesity, resulting in a greater risk of T2D (Stern et al., 1972; Sanjabi et al., 2015). In addition, adipocyte enlargement is associated with insulin resistance in nondiabetic subjects independent of body weight, indicating that changes in adipocyte size modulate insulin sensitivity before the development of T2D (Lundgren et al., 2007). Altogether, these findings indicate that changes in the number and morphology of LDs influence IIS and might contribute to the development of T2D and other pathophysiological conditions.

Obesity research is greatly facilitated by the availability of multiple techniques that enable accurate measurement of the body fat content in $C$. elegans. Total amount of fat in nematodes can be measured chemically by thin layer chromatography (TLC) or biochemically by an enzymatic assay that detects TAGs, the predominant form of fat in worms (Lemieux et al., 2011, Aranaz et al., 2020). Fat levels can also be determined by measuring the vibrations of $\mathrm{C}-\mathrm{H}$ bonds in lipids through coherent anti-Stokes Raman scattering (CARS) microscopy (Rinia et al., 2008). Because the nematode's body is transparent, changes in the fat content can be easily visualised through different staining techniques, e.g. using Oil Red O (ORO), Nile red, Sudan black or Bodipy (Kimura et al., 1997; Hellerer et al., 2007; O'Rourke et al., 2009). Enhanced details such as the number and size of LDs can be determined using fluorescently tagged proteins, e.g. a green fluorescent protein (GFP) tag, localised on their surface. In $C$. elegans LDs' biomarkers such as shortchain dehydrogenases 3 (DHS-3); DGAT-2, a member of the acylCoA synthetase family (ACS-4); and adipose triglyceride lipase 1 (ATGL-1) (Zhang et al., 2010; Xu et al., 2012a; Zhang et al., 2012; Liu et al., 2014; Vrablik et al., 2015) are commonly used to differentiate between LD hyperplasia (increase in the number) and hypertrophy (enlargement), the latter being the main cause of metabolic dysfunction and obesity (Trayhurn, 2007).

\section{Genetic factors regulating energy metabolism in $C$. elegans and mammals}

Different mouse models have played an important role in understanding the function of specific genes in the development of obesity. Although nematodes are physiologically different from humans, they have been used as model organisms to identify regulators of fat metabolism (Ashrafi et al., 2003). Various powerful genetic techniques used in $C$. elegans have enabled to identify novel factors that regulate fat accumulation (Carroll et al., 2004; Ashrafi, 2007; Schlegel and Stainier 2007; Habacher et al., 2016). The functions of putative genes regulating fat storage in $C$. elegans have been investigated using targeted deletions, mutagenesis screens, Crispr/cas9 genome editing approach and a genome-scale RNA interference (RNAi) screening. Genome-wide silencing in C. elegans revealed around 300 genes that decrease fat accumulation and approximately 100 genes that cause an increase in the body fat levels, many of which are functionally conserved in mammals (Ashrafi, 2007).

The evolutionarily conserved IIS pathway is a critical regulator of growth, development and longevity in $C$. elegans (Bulger et al., 2016). Mutation in the gene encoding insulin receptor (daf-2) increases fat accumulation in nematodes (Kimura et al., 1997). Adipose-tissue specific knockout of the insulin receptor (Insr) resulted in severe lipodystrophy and peripheral insulin resistance in the skeletal muscle and liver that led to the development of diabetes, hyperlipidemia and fatty liver disease in mice (Boucher et al., 2016; Softic et al., 2016). Similar to rodents, during the progression from mild to severe obesity, there is an inverse correlation between increasing body mass index (BMI) and decreasing expression of INSR in human visceral white adipose tissue (WAT) (Arcidiacono et al., 2020).

Another gene that affects body fat levels in $C$. elegans is peptide transporter 1 (pept-1), an ortholog of human SCL15A1. PEPT-1 is responsible for the transport of diand tripeptides in the intestine. Primarily, pept-1 mutation in $C$. elegans was found to be associated with the fat loss phenotype (Ashrafi et al., 2003; Nehrke, 2003). However, later studies demonstrated that inhibition of pept-1 increases fat accumulation in nematodes possibly through enhancement of the FA flip-flop diffusion across the intestinal membrane (Brooks et al., 2009; Spanier et al., 2009; Benner et al., 2011). Similarly to nematodes, in humans, PEPT1 transports nutrient-derived diand tripeptides and peptide-mimicking drugs into the gut lumen (Brandsch, 2013). In the human intestinal epithelial cell line Caco-2, PEPT1 membrane abundance 
and dipeptide transport activity are regulated by insulin and leptin hormones (Thamotharan et al., 1999; Buyse et al., 2001; Hindlet et al., 2009). Although insulin has no effect on SCL15A1 mRNA levels, it increases PEPT1 protein levels in the apical membrane of Caco-2 cells (Thamotharan et al., 1999). In Caco-2 cells, leptin increases $S C L 15 A 1$ transcription through the activation of the mitogen-activated protein kinase (MAPK) signalling pathway and enhances PEPT1 protein translation through the ribosomal protein S6 (Hindlet et al., 2009). SCL15A1 mRNA and PEPT1 protein levels as well as its transport activity are decreased in mice fed a hypercaloric diet for 4 weeks. In rodents, PEPT1 lowers postprandial blood glucose levels and improves glycaemic control in the upper small intestine following acute highprotein intake (Dranse et al., 2018). Pept1 knockout mice show reduced body weight and shortened intestinal microvilli, which greatly affects gut homeostasis (Kolodziejczak et al., 2013; Zhang et al., 2016a). In addition, intestinal absorption of peptide-mimicking drugs mediated by PEPT1 is enhanced in hyperinsulinemic T2D rats (Watanabe et al., 2003). Altogether, these findings indicate that PEPT1 maintains proper function and homeostasis in the small intestine and thus contributes to nutrient absorption and uptake of peptidomimetic drugs.

Fat accumulation in $C$. elegans is also increased through mutation in the tubby homolog gene (tub-1) (Ashrafi et al., 2003). In nematodes, TUB-1 affects protein and PL composition of the cilia membrane and stimulates membranous expansion of ciliated sensory neurons (DiTirro et al., 2019). Knockdown of the tub-1 gene causes an increase in RabGTPase-activating protein (RBG-3), which may increase fat storage in $C$. elegans through the modulation of processing and vesicular transport in sensory neurons upstream of the insulin-like signalling pathway (Mukhopadhyay et al., 2005). Most studies on the function of the tubby gene have been conducted in mice, where $\mathrm{G} \rightarrow \mathrm{T}$ transversion was shown to disrupt splicing, resulting in a larger transcript containing an unspliced intron (Noben-Trauth et al., 1996; Sahly et al., 1998; Boggon et al., 1999). This mutation causes the tubby phenotype, which has been implicated in obesity, retinal degeneration and hearing loss ( Kleyn et al., 1996; Ikeda et al., 1999; Stubdal et al., 2000; Jacobson et al., 2014). Genetic variation of the TUB gene influences body weight (Shiri-Sverdlov et al., 2006) and eating behaviour in humans (van Vliet-Ostaptchouk et al., 2008). Recently, in humans, the TUB gene has been shown to be expressed in the hypothalamus; however, no differences in hypothalamic TUB expression with respect to body weight were observed, while adipose TUB expression is lower in subjects with obesity than in the control group (Nies et al., 2017).

A genome-wide screen for regulators of fat metabolism identified that knockdown of different nuclear hormone receptors (NHRs) influences fat storage or lipid catabolism in C. elegans (Ashrafi et al., 2003; Arda et al., 2010). NHR-49 is an ortholog of human hepatocyte nuclear factor 4 alpha and 4 gamma (HNF4A and $\mathrm{HNF} 4 \mathrm{G}$ ), and it is functionally remarkably similar to mammalian peroxisome proliferator-activated receptors which are important regulators of energy metabolism (Van Gilst et al., 2005; Taubert et al., 2006). NHR-49 induces the expression of the delta-9 FA desaturase gene (fat-7) in well-fed worms, whereas upon fasting, it downregulates the expression of fat- 7 and mitochondrial $\beta$-oxidation genes such as a carnitine palmitoyl transferase-1 isoform (cpt-4), short-chain acyl-CoA dehydrogenases (acdh-1 and acdh-2) and enoyl-CoA hydratase genes (ech-1 and ech-6) (Van Gilst et al., 2005). NHR-49 regulates many signalling pathways involved in lipid metabolism through interaction with multiple transcriptional co-factors. NHR-13 and NHR-80 receptors associate with NHR-49 to stimulate the expression of FA desaturases, namely fat-7, fat-5 and fat- 6 , which regulate the ratio of saturated and unsaturated FAs in lipid membranes (Pathare et al., 2012). NHR-49 interacts with NHR-66 to repress genes encoding enzymes involved in sphingolipid breakdown, e.g. FA ceramidase, glycosyl hydrolase and sphingosine phosphate lyase, and lipolysis, e.g. phospholipases, TAG lipase and O-acyltransferase (Pathare et al., 2012). Knockdown of nhr-64 increases body fat content through enhanced de novo synthesis of monomethyl branched chain FAs and expression of ACC (Liang et al., 2010). NHR-69 also regulates the secretion of neuropeptides, including the insulin-like peptide DAF-28, and thus increases IIS and lowers glucose levels in ASI neurons, functionally resembling the mammalian pancreas (Park et al., 2012). In humans, single nucleotide polymorphisms (SNPs) in the $H N F 4 A$ gene contribute to the development of maturity-onset diabetes of the young (MODY), which is a noninsulindependent T2D mellitus (NIDDM) (Yamagata et al., 1996; Saif-Ali et al., 2011). Recent studies have demon- 
strated that overweight children have decreased methylation of $H N F 4 A$ in their cord blood as compared to children with normal body weight (Kwon et al., 2019). Moreover, in overweight and obese children, hypomethylation of $H N F 4 A$ in promoter $\mathrm{P} 1$ and hypermethylation of $H N F 4 A$ in promoter $\mathrm{P} 2$ are associated with higher total cholesterol and TAG levels (Kwon et al., 2018). Knockdown of $H N F 4 A$ in human hepatoma cell lines inhibits the secretion of TAGs and apolipoprotein B as well as the expression of genes regulating lipid and lipoprotein metabolism (Krapivner et al., 2010). The absence of Hnf4a in the visceral endoderm (VE) of murine embryoid bodies, sharing many functional properties with the liver and pancreatic beta-cells ( $\beta$-cells), inhibits the expression of genes involved in glucose and lipid metabolism (Stoffel and Dunkan, 1997). Hnf4a -deficient mice are characterised by hepatic steatosis and increased serum levels of TAG, total cholesterol and high-density lipoprotein (HDL) cholesterol (Hayhurst et al., 2001). Recently, it has been shown that rats overexpressing Hnf4a fed with a high-fat diet (HFD) have significantly reduced liver TAG and WAT, lower body weight and increased HDL/low-density lipoprotein (HDL/LDL) cholesterol ratios (Huang et al., 2020). Altogether, these findings indicate that HNF4A-like NHRs in nematodes, alike in mammals, are involved in the regulation of glucose and lipid metabolism.

Fat storage in nematodes is also decreased upon mutations in genes encoding delta-9 FA desaturases (fat-5, fat-6 and fat-7) (Brock et al., 2007). In C. elegans and mammals, stearoyl-CoA desaturase (SCD) catalyses the biosynthesis of monounsaturated FAs (MUFAs) from saturated FAs (SFAs) (Brock et al., 2007; ALJohani et al., 2017). In $C$. elegans, palmitic acid (16:0), obtained from dietary $E$. colior synthesised de novo, is converted by FAT- 5 to palmitoleic acid $(16: 1)$ or elongated by FAT-6 and FAT-7 to stearic acid (18:0), which is further processed to form PUFAs (Watts and Browse, 2002). PUFAs influence cell membrane composition, modulate lipid signalling and are required for growth, neurotransmission and reproduction (Kahn-Kirby et al., 2004 Watts and Ristow, 2017). Moreover, delta-9 FA desaturases are essential for $C$. elegans survival, as seen in worms with triple mutations in fat-5; fat-6; fat-7, which is lethal due to an inability to produce MUFA (Brock et al., 2006). Deletion of a single gene encoding FA desaturase leads to a subtle phenotype due to compensatory func- tion of the other desaturases (Brock et al., 2006). Disturbance in delta-9 FA desaturases reduces the amount of TAG, resulting in decreased body fat (Brock et al., 2007). Humans have two known isoforms of SCD, namely SCD1 and SCD5 (Wang et al., 2005). SCD1 plays an important role in the regulation of fat metabolism, and its overexpression leads to the development of nonalcoholic fatty liver disease (NAFLD), obesity and hyperlipidaemia (Mar-Heyming et al., 2008; Vinknes et al., 2013; Suppli et al., 2019). SNPs in the $h S C D 1$ gene cause a decrease in waist circumference and an increase in insulin sensitivity (Warensjo et al., 2007). In mice, $S c d 1$ deficiency increases the activity of the AMP-activated protein kinase (AMPK), which enhances the expression of catabolic genes and leads to body weight loss (Dobrzyn et al., 2004). Mice with hepatic Scd1 knockout are characterised by the up-regulation of genes responsible for lipid oxidation, e.g. Ppara, and down-regulation of genes involved in lipid synthesis, e.g. FA synthase (Fasn), which leads to decreased TAG plasma levels and increased energy expenditure and insulin sensitivity (Miyazaki et al., 2000; Ntambi et al., 2002). Moreover, Scd1-null mice are protected against HFD-induced obesity due to increased SFA/MUFA ratio, which leads to reduction in fat accumulation (Ntambi et al., 2002; Al Johani et al., 2017).

Knockdown of cathepsin L-like protease ( $c p l-1)$ reduces fat accumulation in $C$. elegans via activation of the serotonin signalling (Lin et al., 2019a). In mice, loss of the cathepsin $\mathrm{L}$ gene (CatL) reduces body weight gain and WAT adipogenesis and increases WAT lipolysis and FA $\beta$-oxidation (Lin et al., 2019a). Moreover, CatL-null mice are lean and have reduced serum glucose and insulin levels and increased levels of glucose transporter 4 (GLUT4) (Yang et al., 2007). Similarly, CatL-deficient mice fed with an HFD accumulate significantly less fat through increased adipocyte lipolysis, have reduced brown adipose tissue (BAT) mass and have lower plasma TAGs, cholesterol and leptin levels as compared to wildtype (WT) animals (Funicello et al., 2007). Moreover, cathepsin K (CatK) deficiency in mice increases the amount of GLUT4 in adipose and muscle tissues and reduces plasma insulin and glucose levels (Yang et al., 2008). Incubation with a nonselective cathepsin inhibitor E64d inhibits adipogenesis of 3T3-L1 cells, while overexpression of CatK enhances cell differentiation (Yang et al., 2008). Humans have two forms of cathepsin, namely L1 (CTSL1) and B (CTSB). The expression of 
CTSL1 is upregulated in the abdominal subcutaneous WAT in individuals with obesity and positively correlated with the level of adiposity, while the expression of $C T S B$ is reduced and correlates with insulin resistance $(\mathrm{Xu}$ et al., 2020). These data indicate that cathepsin signalling influences glucose and lipid metabolism in both nematodes and mammals.

\section{Post-transcriptional regulation of fat accumulation and adipogenesis}

Mutation in the gene encoding an endoribonuclease (rege-1) decreases body fat levels in $C$. elegans (Habacher et al., 2016). REGE-1, a close homolog of the mammalian MCPIP1/Zc3h12a/Regnase-1 (Xu et al., 2012; Habacher et al., 2016; Habacher and Ciosk, 2017) regulates the expression of genes involved in lipid metabolism and immunity by targeting mRNA encoding a transcription factor (ETS-4) (Habacher et al., 2016). Both worm REGE-1 and mammalian Regnase- 1 cleave target mRNAs in their $3^{\prime}$ - UTR regions (Habacher and Ciosk, 2017). Mammalian Regnase- 1 is involved in posttranscriptional control of a subset of mRNAs in different cell types and thus plays an important role in the regulation of immune homeostasis and cellular adaptation in multiple pathophysiological conditions, including autoimmune disorders and cancer (Habacher and Ciosk, 2017; Mao et al., 2017). However, the functional role of Regnase- 1 in the regulation of adipogenesis remains controversial. In 3T3-L1 cells, Regnase-1 has been shown to induce adipogenesis by increasing the expression of the CCAAT enhancer-binding protein beta $(C e b p b)$ without an effect on the master adipogenic regulator peroxisome proliferator-activated receptor gamma ( $P$ parg) (Younce et al., 2009). In addition, Mcpip1 overexpression induces adipogenesis in 3T3-L1 cells through increased production of reactive oxygen/nitrogen species and expression of inducible-nitric oxide synthase (iNOS), which lead to ER stress and autophagy (Younce et al., 2012). In contrast, in a similar experiment by Lipert et al. (2014), inhibition of Mcpip1 increases Cebpb and Pparg mRNA levels and thus stimulates differentiation of 3T3-L1 cells. Similarly, overexpression of Mcpip1 in 3T3-L1 fibroblasts reduces the mRNA levels of proteins involved in adipocyte differentiation (Pparg, CCAAT enhancer-binding protein alpha (Cebpa)), insulin-stimulated glucose uptake (Slc2a4 and Tbc1d4) and carbohydrate metabolism (Mgat1) (Losko et al., 2020). In addition, the ex- pression of genes involved in TAG biosynthesis (Dgat2 and Srebf1), FA metabolism (Elovl1 and Stat5A), lipid metabolism ( $S c d 1$ and $L p I)$ and dicarboxylic acid transport (Slc25a10) is reduced in Mcpip1-overexpressing cells (Losko et al., 2020). Elevated Mcpip1 expression decreases the amount and activation of insulin receptor (IR) and reduces insulin-induced serine/threonine-protein kinase (AKT) phosphorylation and thus attenuates IIS in 3T3-L1 cells (Losko et al., 2020). MCPIP1 mRNA levels are higher in women with obesity than in lean individuals (Lipert et al., 2014). In contrast, more recent data from the same group show that $M C P I P 1$ expression in subcutaneous adipose is inversely correlated with BMI (Losko et al., 2020). These discrepancies in the MCPIP1 mRNA levels result from the limitation of the availability of human samples and the type of control used in each study. Current findings on the role of Regnase- 1 in the regulation of fat accumulation and adipogenesis in mammals are inconsistent. As REGE-1 is an ortholog of mammalian Regnase-1, the use of $C$. elegans might help to reveal the role and discover the molecular basis of Regnase-1-mediated fat metabolism in humans.

\section{The insulin signalling pathway modulates fat metabolism}

Obesity develops due to a chronic increase in food intake and insufficient physical activity. In humans, food intake is regulated predominantly by two hormones, namely leptin secreted by the AT and insulin produced by pancreatic $\beta$-cells (Niswender and Schwartz, 2003). Although nematodes lack some signalling pathways crucial for the regulation of metabolism in mammals, e.g. leptin signalling, similar to humans, their fat storage strongly depends on the IIS pathway (Kimura et al., 1997). In C. elegans, the IIS pathway is the major regulator of fat accumulation. DAF-2 is activated by an insulin-like ligand, and by binding to its receptor, DAF-2 activates a signalling cascade that results in the phosphorylation of the abnormal dauer formation 16 (DAF-16), the ortholog of human forkhead box (FOXO) transcription factor, which sequesters DAF-16 in the cytoplasm (Kimura et al., 1997). Mutation in the daf-2 gene prevents downstream phosphorylation of DAF-16, thereby enabling its nuclear transport. In the nucleus, DAF-16 stimulates the expression of genes that regulate growth and lifespan as well as fat and glucose metabolism, e.g. pantothenate kinase (pnk-1) encoding pantothenate kinase (PanK) involved in 
coenzyme A biosynthesis (Lee et al., 2003); fat-7 necessary for the synthesis of unsaturated FAs (Murphy et al., 2003); gluconeogenic genes, e.g. phosphoenolpyruvate carboxykinase PEPCK (pck-1 and pck-2) and pyruvate carboxylase (pyc-1) (McElwee et al., 2006), leading to an increase in body fat content. In addition, DAF-16 affects the expression of genes at a distance via the lipid-gene mediator 15 (MDT-15) (Zhang et al., 2013). Mutation in the daf-16 gene leads to an almost complete recovery of the daf-2 mutant phenotype (Kimura et al., 1997), further indicating that DAF-16 is the major regulator of fat accumulation in $C$. elegans. Dysfunction of the insulin signalling in mammals leads to hepatic lipid accumulation and impairs glucose metabolism and insulin sensitivity in muscle and liver (Bugianesi et al., 2005), while in C. elegans, an equivalent increase in the intestinal fat stores is observed (Shi et al., 2013). Hyperactive IIS in humans leads to the development of different types of cancers, e.g. glioblastomas, gastric cancers, breast cancers and lung cancers, while loss of the IIS pathway results in insulin resistance and the development of T2D (Niswender and Schwartz, 2003; Samuels et al., 2004; Lindhurst et al., 2012).

In humans, an adequate level of glucose is maintained through simultaneous action of insulin and glucagon. After meal consumption, glucose administered with food stimulates insulin production from pancreatic $\beta$-cells, which enhances glucose absorption from the bloodstream and increases energy production (Röder et al., 2016). High-sugar diet (HSD) and HFD increase body fat levels in mammals and $C$. elegans. Under hyperglycaemic conditions, insulin's ability to lower blood glucose levels is impaired, which leads to a decrease in cell surface GLUT4 levels in the skeletal muscle (Shepherd and Kahn, 1999; Marette et al., 1999; Czech, 2017). This leads to reduced glucose uptake from the circulation into the muscle and deposition of excess glucose as fat in the AT, and might result in the development of obesity in mammals (Leahy et al. 1986; Kim et al., 2001). In C. elegans, HSD increases fat storage and generation of reactive oxygen species (ROS), reduces lifespan and promotes dauer formation (Garcia et al. 2015; Wang et al., 2020; Kingsley et al. 2021). Moreover, glucose increases body fat levels by promoting lipid biosynthesis through stimulation of the expression of transcription factor SBP-1, an ortholog of mammalian sterol regulatory element binding protein (SREBP1), which regulates adipo- genesis and lipid biosynthesis (McKay et al., 2003; Nomura et al., 2010), through the up-regulation of fat-5, long-chain acyl-CoA synthetases (acs-2, acs-15, and acs- 8 ) and ceramide glycosyl transferase (cgt-1) mRNA levels (Garcia et al. 2015). In addition, the expression of genes related to carbohydrate metabolism, e.g. glycolytic, gpd-2, and $g p d-3$; gluconeogenic genes, namely $p c k-1$ and $p c k-3$; and transport, e.g. sugar transporter, swt-1, increases in response to HSD treatment (Garcia et al. 2015).

Excessive consumption of lipids in relation to caloric requirements leads to their ectopic accumulation in nonadipose tissues and impairs insulin response. In mammals, prolonged exposure to high amounts of lipids, such as ceramides, gangliosides, and diacylglycerols, can be toxic for pancreatic $\beta$-cells, resulting in lipotoxicity, which leads to insulin resistance and T2D (Schooneman et al., 2013; Larsen and Tennagels, 2014). In C. elegans, high-glucose and high-lipid diets up-regulate the expression of fat-1, fat-2, fat -3 , fat-4, and fat-5 genes, which produce high amounts of PUFAs and thus might lead to the development of metabolic disorders (Wang et al., 2020). Similarities in metabolic effects of the IIS in worms and humans indicate that nematodes are useful model organisms to study the molecular mechanisms resulting from disruption of the IIS pathway.

\section{Bacterial diet influences fat storage in C. elegans}

Food is the main source of energy essential for the survival of all living organisms. Excessive calorie consumption in relation to the amount of calories burned has undesirable consequences for human metabolism and may lead to the development of obesity, cardiovascular diseases and T2D (Tilman and Clark, 2014). In C. elegans, as in mammals, changes in the source and availability of food affect the rate of food intake, activity of certain metabolic pathways and body fat content. Because $C$. elegans feeds on bacteria, including Escherichia coli, which are found in the human gut microbiota, through feeding worms with various bacterial strains, the influence of diet on host health can be studied (MacNeil et al., 2013). In natural habitats, C. elegans consume different types of soil bacteria, e.g. Comomonas sp., Pseudomonas medocina and Bacillus megaterium (Avery and Shtonda, 2003). Under standard laboratory conditions, three main types of $E$. coli, namely OP50, HB101 and HT115, are usually used. Bacterial strains 
used as a diet contain different compositions of FAs, amino acids (AAs) and PLs, which have a significant impact on fat metabolism in worms (Gao et al., 2017). To form TAGs, $C$. elegans needs certain types of FAs supplied exclusively with a bacterial diet (Gao et al., 2017). OP50 is used as a standard food for laboratory worms, as it provides relevant FAs needed for TAG synthesis (Stiernagle, 2006). In addition, it forms a thin lawn on the agar plate, which allows to visualise $C$. elegans under the microscope (Stiernagle, 2006). HB101 E. coli strain contains higher levels of $\mathrm{C} 16: 0$ and $\mathrm{C} 18: 2 \mathrm{n} 6 \mathrm{FAs}$ and lower amounts of $\mathrm{C} 18: 0 \mathrm{FAs}$ in comparison to OP50 (Zhang et al., 2010). HB101 does not produce the vaccenic acid (C18:1n7) needed for TAG production, which results in the reduction of $\mathrm{LD}$ size and lower fat accumulation in C. elegans (Zhang et al., 2010; Gao et al., 2017; Stuhr and Curran, 2020). The third type of bacteria, commonly used in RNAi experiments, is the HT115 strain. The overall body fat levels in worms fed with HT115 are greater than that in nematodes fed with OP50, presumably due to different composition of AAs, despite similar FA content. Worms fed with HT115 strain contain higher levels of aspartate, glutamate and lysine (Reinke et al., 2010). In addition, the level of betaine, glucose, lactate and o-phosphocholine are greater, whereas the amount of acetate is lower in worms fed with HT115 than in worms fed with OP50 bacteria (Reinke et al., 2010; Stuhr and Curran, 2020). Other bacteria species such as Methylobacterium and Sphingomonas, which often appear as contamination of plates seeded with OP50, affect fat metabolism in C. elegans due to significant differences in nutrient composition (Stuhr and Curran, 2020). Methylobacterium contains higher levels of glycerol, glucose and water, while Sphingomonas contain higher levels of glycerol and water in comparison to OP50 strain. Consumption of these bacterial strains decreases fat accumulation in C. elegans probably due to increased expression of fat-5 and fat-7 (Stuhr and Curran, 2020). Altogether, these results demonstrate that bacterial strains used as food for nematodes differ in their nutrient composition and might affect the expression of fat metabolism genes and consequently change the body fat content.

\section{Gut microbiota modulates fat accumulation in nematodes and mammals}

Micronutrients administered with food are absorbed along the gastrointestinal tract and modulate health, body weight gain and composition of the gut microbiota (Zhao et al., 2018). Most human microbiota are found in the intestine, where they form a complex ecosystem (Frank et al., 2007) composed of bacteria, archaea, viruses, fungi and protozoa (Davis, 2016). The gut microbiota plays a crucial role in maintaining homeostasis through modulation of the intestinal digestion, production of vitamins $\mathrm{B}$ and $\mathrm{K}$, maintenance of structural integrity of the gut mucosal barrier and regulation of the immune system function by preventing multiplication of pathogenic microorganisms and enhancing drug metabolism (Jandhyala et al., 2015; Davis, 2016). On the other hand, gut microbiota may promote proliferation of cancer cells by interacting with the immune system or through modulation of cancer immunosurveillance (Jain et al., 2021).

The composition of gastrointestinal microbiota affects energy balance and might lead to the development of multiple diseases, e.g. inflammatory bowel disease (IBD), irritable bowel syndrome (IBS), allergies and metabolic diseases including obesity and T2D (Turnbaugh et al., 2006; Jandhyala et al., 2015). The presence and composition of the gut microbiota are important for the maintenance of body homeostasis, including regulation of body fat content. Germ-free (GF) mice contain lower body fat levels than their WT counterparts (Backhed et al., 2004). Moreover, transplanting microbiota from WT to GF mice increases fat accumulation without an increase in food consumption. Greater body fat content likely results from the fact that gut microbiota induces monosaccharide absorption from the gut lumen and promotes de novo hepatic lipogenesis, which leads to increased fat accumulation (Backhed et al., 2004). Many organisms are unable to digest, absorb and obtain energy from dietary nutrients. The gut microbiota enables carbohydrate and polysaccharide metabolism, absorption of monosaccharides and short-chain FAs and FA conversion to complex lipids and thus might promote fat accumulation (Turnbaugh et al., 2006).

Although the human gut microbiota varies between geographical location and type of diet (Stanislawski et al., 2019), the dominance of two groups of bacteria, namely Bacteroidetes and Firmicutes, is noticeable (Jain et al., 2021). People living in Africa contain higher levels of Bacteroidetes and lower levels of Firmicutes than Italian citizens (De Filippo et al., 2010). Diet rich in fruits, vegetables and fibres increases the diversity of gut microbiota and the abundance of microorganisms metabo- 
lising insoluble carbohydrates of the Firmicutes phylum, e.g. Ruminococcus bromii, Roseburia and Eubacterium rectale (Walker et al., 2011). In contrast, meat-based diets decrease the number of Firmicutes and increase Alistipes sp. and Bacteroides sp. like bacteria from Bacteroidetes and Bilophila sp. phyla (David et al., 2014).

The composition of gut microbiota might affect human health. People suffering from obesity have higher levels of Firmicutes and lower levels of Bacteroidetes than lean individuals (Jie et al., 2021). In contrast, people with obesity consuming low-calorie diets contain higher intestinal levels of Bacteroidetes and lower levels of Firmicutes (Ley et al., 2006; Turnbaugh et al., 2006), further indicating that the ratio of Firmicutes to Bacteroidetes affects obesity. In individuals with obesity, higher levels of Firmicutes might enhance intestinal FA absorption, which might lead to increased body weight gain (Turnbaugh et al., 2006). GF mice colonised with Bacteroidetes, which is a member of adult human intestinal microbiota, are characterised by improved lipid absorption and processing (Hooper et al., 2001). Therefore, modulating the composition of the gut microbiota may be important in the prevention and treatment of obesity and other metabolic diseases.

In $C$. elegans, the type of bacteria serving as a food source affects energy balance, fat accumulation and composition of the gut microbiota. In addition to Proteobacteria and Actinobacteria, intestinal microbiota in nematodes contain bacteria from Firmicutes and Bacteroidetes phyla (Samuel et al., 2016; Zimmermann et al., 2020) also found in the human microbiota. Caenorhabditis elegans microbiota plays an essential role in the regulation of stress resistance (Dirksen et al., 2016), pathogen protection (Kissoyan et al., 2019) and synthesis of essential nutrients (Zimmermann et al., 2020). Nematode's microbiota co-metabolises fluoropyrimidines used in chemotherapy and thus determines the efficiency of anticancer treatment (Scott et al., 2017). Similarly, dietary thymidine stimulates microbial conversion of the prodrug 5-fluoro 2 deoxyuridine (FUdR) into toxic 5-fluorouridine-5 -monophosphate (FUMP), leading to autophagy and death in C. elegans (Ke et al., 2020).

In the past 15 years, a functional link between gut microbiota and the development of obesity has been extensively studied. However, because of difficulties in human research, including sample availability, variations in sample acquisition and technical limitations, specific molecular mechanisms through which intestinal bacteria affect host metabolism in health and disease remain to be identified (Maruvada et al., 2017; Aoun et al., 2020). Recent identification of the gut microbiota in $C$. elegans and similarities between nematode and human gut microbiota might facilitate microbiome-obesity research, which has so far been impeded by technical limitations and availability of a good experimental model. The use of $C$. elegans as a model organism in determining drug-microbiome-host interactions might help to understand the origins of pharmacokinetic variations between individuals and to test the toxicity of different pharmacological obesity interventions.

\section{Metabolic effects of natural bioactive compounds on fat accumulation}

Most of the available obesity treatments include medications that inhibit absorption of fat in the intestinal lumen or decrease appetite and therefore affect food intake. Like other synthetic drugs, these medications exert multiple side effects ranging from mild, e.g. nausea, dizziness, headache and dry mouth, to serious health implications, e.g. liver damage and pancreatitis. Because obesity is a global problem and many people suffer from obesity-related diseases, searching for natural safe bioactive compounds that can enrich diet and reduce excessive fat accumulation and/or burn fat is highly desirable.

Among the bioactive compounds that significantly reduce the lipid content of $C$. elegans are flavones (apigenin and luteolin), phenolic compounds (resveratrol) and phenolic acids (vanillic acids and p-coumaric acids) (Aranaz et al., 2020). The flavonoid apigenin is found in many fruits and vegetables, e.g. parsley, celery, celeriac and chamomile tea. Apigenin decreases the body fat content in nematodes and mammals by up-regulating lipl-5, which encodes a TAG lipase. lipl-5, which is an ortholog of human LIPA (lipase A, lysosomal acid type), LIPF (lipase F, gastric type) and LIPM (lipase family member M) genes, catalyse the conversion of TAGs to free FAs (FFAs) and glycerol (Choi et al., 2017; Aranaz et al., 2019; Aranaz et al., 2020). Luteolin, naturally found in celery, broccoli, artichoke, green pepper, parsley, thyme, dandelion, carrots, olive oil, peppermint, rosemary and oregano, promotes serotonin signalling and induces lipolysis and FA $\beta$-oxidation in worms (Xu et al., 2014; Lin et al., 2020). In mammals, luteolin inhibits adipogenic differentiation through the activation 
of AMPK and sirtuin 1 (SIRT1) and protects against HFD-induced body weight gain, fat mass accumulation and insulin resistance (Zhang et al., 2016). Moreover, consumption of other flavons might reduce fat accumulation in mammals and humans. Green tea, containing many flavonoids such as catechins, decreases 3T3-L1 cell adipogenesis through the up-regulation of the WNT/ß-catenin signalling pathway (Lee et al., 2013). In murine hepatic and fibroblast cell lines, catechins increase AMPK $\alpha$ activity, which induces phosphorylation of its downstream target, ACC, resulting in enhanced oxygen consumption and FA $\beta$-oxidation (Murase et al., 2009). Tea catechins also enhance uncoupling protein 1 (Ucp1) expression in BAT and reduce fat accumulation in rats fed HFD possibly through enhanced non-shivering thermogenesis (Nomura et al., 2008). Similarly, in humans, tea catechins lower body fat content by activating and recruiting BAT, leading to increased energy expenditure and FA $\beta$-oxidation (Dulloo et al., 1999; Nomura et al., 2008). Various food ingredients, e.g. catechins from green tea or capsaicin from red pepper, activate transient receptor potential (TRP) superfamily cation channels, which are expressed in the sensory nerve endings, present on the body surface and by mimicking the effects of cold lead to reduction in human fat mass (Dulloo et al., 1999). Supplementation with flavonoid-rich extracts isolated from Citrus aurantium L. var. amara $\mathrm{Engl}(C A V A)$ reduces TAGs levels and expression of multiple genes regulating lipid and glucose metabolism, e.g. mdt-15, fat-2, fat-4, fat-5, fat-7, nhr-49 and acs-2 in WT worms (Shen et al., 2019). Similarly, CAVA treatment prevents adipocyte hypertrophy, body weight gain and liver steatosis in mice fed HFD. CAVA administration also influences composition of the gut microbiota by decreasing the Firmicutes-to-Bacteroidetes ratio.

Resveratrol, an example of phenolic compounds, produced by several plants, e.g. grapes, blackberries, raspberries, strawberries and apples, reduces fat accumulation in nematodes by down-regulating the expression of genes involved in lipid biosynthesis, FA elongation, FA $\beta$-oxidation, lipid storage and transport, and enhancement of genes regulating lipolysis (Aranaz et al., 2020). In rodents, resveratrol mimics the effects of calorie restriction and reduces fat accumulation through activation of Sirt1 (de Ligt et al., 2015; Imamura et al., 2017). Meta-analysis of randomised controlled trials showed that phenolic compounds such as resveratrol reduce body weight and fat mass, increase lean mass, but have no effect on leptin and adiponectin levels in humans (Tabrizi et al., 2020).

Phenolic acids such as vanillic acid, which occurs in argan oil, vinegar and wine, induce changes in the expression of genes involved in the antioxidant and stress resistance response, which might underlie its fat-reducing activity in $C$. elegans (Aranaz et al., 2020). Vanillic acid decreases body weight gain and suppresses the expression of transcription factors crucial for adipogenesis, e.g. Pparg and Cebpa, in WAT from mice with diet-induced obesity (Jung et al., 2018). Dietary phenolic acids, e.g. chlorogenic acid, ellagic acids and p-coumaric acid, found in many fruits and vegetables have a positive effect on human health (Vinayagam et al., 2015). Through their anti-diabetic potential, they inhibit carbohydrate digestion and intestinal glucose absorption and stimulate insulin secretion (Vinayagam et al., 2015). Dietary phenols such as p-coumaric acid in rat L6 skeletal muscle cells (Yoon et al., 2013), ellagic acid in rat aortic smooth muscle cells (Rani et al., 2013) and chlorogenic acid in mice hepatic tissue (Ong et al., 2013) can also improve lipid metabolism by preventing lipid deposition. Dietary phenols improve glucose and lipid metabolism in rodent models of obesity through the activation of the AMPK signalling pathway (Kang et al., 2012; Ong et al., 2013). p-Coumaric acid in C. elegans has antioxidant properties and enhances worm survival under oxidative and osmotic stress conditions (Yue et al., 2018). Similarly, cranberry phenolic compounds lower fat accumulation in $C$. elegans by regulating the expression of $s b p-1, c e b p$ and $n h r-49$ (Sun etal., 2016).

Bioactive compounds from broccoli (Brassica oleracea) extract significantly reduce body weight and food intake in C. elegans (Aranaz et al., 2019a) and reduce fat accumulation and adipocyte size in rodents through down-regulation of adipogenic transcription factor (Cebpa) and lipogenesis mediators (Srebp1 and Fasn) (Aranaz et al., 2019a). Bioactive compounds such as omega-6 FAs from Borago officinalis seed oil induce fat loss in $C$. elegans and rodents through the activation of peroxisomal FA $\beta$-oxidation (Navarro-Herrera et al., 2018; Navarro-Herrera et al., 2018a). Momordica charantia, commonly known as bitter melon, is often used in India, Asia, South America and East Africa to treat obesity and T2D (Grover and Yadav, 2004). Saponin-enriched ethanol extract from $M$. charantia promotes fat loss in lean and obese worms fed HFD and HSD, al- 
though it has no effect on the pharyngeal pumping rate (Lin et al., 2019). M. charantia extract decreases the expression of mediator of RNA polymerase II transcription subunit 15 (mdt-15), sbp-1, nhr-49, and downstream FA desaturases, namely fat -5 , fat 6 and fat-7, indicating that the inhibition of MUFAs biosynthesis results in decreased average LD size (Lin et al., 2019).

Legumes, which are a rich source of carbohydrates, proteins, fibre, vitamins and minerals, have antioxidant properties, reduce cholesterol absorption and lower blood cholesterol levels (Cakir et al., 2019). In C. elegans, legumes, e.g. light red kidney, black, navy, white kidney and cranberry reduce fat accumulation and increase the pharyngeal pumping rate presumably through the modulation of the serotonin signalling pathway (Finley et al., 2013). In addition, legumes such as resistant starch and fermented starch, obtained from the ceca of mice, decrease body fat content in nematodes possibly through increased energy expenditure or reduced food intake (Zheng et al., 2010). In rodents, resistant starch stimulates the synthesis of short-chain fatty acids (SCFAs), which increase the production of gut satiety hormones, insulin sensitivity, energy expenditure and mitochondria function and increase gastrointestinal motility (Keenan et al., 2006; Gao et al., 2009). Nematodes fed powdered oats containing $\beta$-glucan, which is a soluble dietary fibre, are characterised by reduced intestinal fat deposition and increased pharyngeal pumping rate (Gao et al., 2015). In mammals, $\beta$-glucan increases viscosity in the gastrointestinal tract, delays nutrient digestion and absorption, lowers plasma total and low-density lipoprotein (LDL) cholesterol levels and reduces lipid accumulation (El Khoury et al., 2012).

Altogether, these results demonstrate that natural bioactive compounds affect broad spectra of molecular mechanisms regulating obesity phenotype and therefore are relevant candidates for antiobesity treatment. Because many bioactive compounds affect fat metabolism in both mammals and nematodes, $C$. elegans might serve as a predictive model organism to investigate the role of new bioactive compounds in lipid metabolism.

\section{Stress factors affect body fat content} Dietary restriction reduces fat accumulation through
central and peripheral signalling

Well-fed organisms obtain energy from the utilisation of nutrients administered with food. In rodents, star- vation activates the transcription of genes responsible for lipid catabolism, which allows the use of internal energy reservoirs necessary for animal survival. DR promotes utilisation of fat stores and thus leads to a decrease in body weight and an increase in insulin sensitivity and oxidative stress resistance (Bauer et al., 2004). In mammals, DR reduces the risk of the development of T2D and has a positive effect on health by lowering brain-reactive antibodies, reducing tumour growth, maintaining neural/cognitive function and increasing lifespan (Trepanowski et al., 2011).

In C. elegans, limited availability of food leads to starvation (Avery and Horvitz, 1990). During starvation, changes in nematode metabolism occur due to increased secretion of neuronal signals, e.g. 5-HT (Sze et al., 2000; Gray et al., 2005). These neuronal signals activate a signalling cascade, leading to reduced fat accumulation (Lin et al., 2020). In nematodes, 5-HT is produced through the conversion of tryptophan by tryptophan hydroxylase 1 (TPH-1). During starvation, nematodes produce high levels of 5-HT which binds to serotonin-gated chloride channel (MOD-1) and 5-HT/octopamine receptor 6 (SER-6) and promote FA $\beta$-oxidation through increased ATGL-1 (Srinivasan et al., 2008; Noble et al., 2013). Similarly, long-term administration of exogenous 5-HT to worms decreases fat content and increases energy expenditure as evidenced by enhanced oxygen consumption rate (Srinivasan et al., 2008). In contrast, deletion mutation in the tph-1 gene prevents 5 -HT production, leading to worm arrest at the dauer stage and increased fat accumulation (Sze et al., 2000). These findings demonstrate that upon food deprivation, the serotonin signalling pathway modulates fat content in worms by promoting FA $\beta$-oxidation. In addition to the peripheral regulation of fat metabolism, 5-HT modulates feeding behaviour in worms through an independent molecular mechanism (Srinivasan et al., 2008).

In mammals, serotonergic effects on fat metabolism are correlated with its inhibitory effects on food intake in the central nervous system. However, emerging evidence suggests that locally produced 5-HT influences nutrient absorption and energy metabolism through distinct receptors present in peripheral tissues (Yabut et al., 2019). Mice lacking functional 5-HT receptors (5HT2C) are hyperphagic and develop obesity, insulin resistance and T2D (Tecott et al., 1995; Nonogaki et al., 1998). In contrast, treatment with 5-HT receptor ago- 
nists reduces appetite and induces anorexia in rats (Kennett et al., 1987; Garfield and Heisler, 2009). Similarly, autosomal recessive mutation in mice (anx/anx) results in 5-HT overexpression, which leads to anorexic behaviour, starvation and consequently death (Son et al., 1994). 5-HT treatment protects mice against late onset HFD-induced obesity through inhibition of intra-abdominal fat accumulation and adipocyte hypertrophy, reduction of hyperglycaemia and insulin resistance, and increased energy expenditure (Watanabe et al., 2016). In humans, 5-HT receptor agonists have been used to suppress appetite and increase energy expenditure with limited efficacy and multiple side effects (Chan et al., 2013).

Body fat content in response to DR can also be modulated by two major nutrient-sensing pathways: mTOR and AMPK signalling. The mTOR signalling pathway senses and responds to environmental signals through the regulation of organismal growth, metabolism and lifespan (Laplante and Sabatini, 2012). In rodents, HFD treatment impairs the ability of leptin to activate hypothalamic mTOR, leading to increased food intake and development of obesity (Cota et al., 2008). In C. elegans, stress conditions such as starvation inhibit the mTOR signalling pathway and activate a signalling cascade, leading to a decrease in the body fat content through increased expression of catabolic enzymes, e.g. atgl-1 involved in lipolysis and fatty acid $\mathrm{CoA}$ synthetase family (acs-2) that regulates FA $\beta$-oxidation (O'Rourke and Ruvkun, 2013; Srinivasan, 2015; Harvald et al., 2017; Macedo et al. 2019; Zaarur et al., 2019). Ataxin-2 homolog (atx-2), an ortholog of the human Ataxin-2 (ATXN2), negatively regulates the mTOR signalling in $C$. elegans (Bar et al., 2016). DR activates atx-2, which promotes fat loss in C. elegans through inhibition of mTOR signalling. Down-regulation of atx-2 in dietary-restricted $C$. elegans increases animal size and body fat levels, whereas atx-2 overexpression reduces fat accumulation (Bar et al., 2016). Similarly, Atxn2 knockout mice are obese and have decreased expression of Insr (Kiehl et al., 2006; Meierhofer et al., 2016). These findings suggest that the role of ATXN2 in the regulation of fat metabolism is conserved. Thus, further investigation of molecular mechanisms of DR leading to activation of the ATXN2 signalling pathway might have a significant effect on the development of new therapeutic strategies for obesity treatment.
In $C$. elegans, opposite to mTOR, the AMPK signalling pathway is activated in response to stress conditions, including limited food availability. AMPK is a conserved eukaryotic protein that functions as a nutrient and energy sensor to maintain energy homeostasis when ATP levels are scarce (Hardie et al., 2012). In mammals, AMPK is activated through phosphorylation upon limited energy availability manifested by an increase in the AMP/ATP ratio. In nematodes, an increase in the AMP/ATP ratio leads to phosphorylation of AMP-activated protein kinases AAK-1 and AAK-2, which are orthologs of the mammalian AMPK catalytic subunits $\alpha 1$ and $\alpha 2$ (Apfeld et al., 2004). DR activates AAK which upregulates the expression of genes modulating oxidative metabolism through the regulation of DAF-16 transcription factor (Greer et al., 2007). AAK-2 activation by 5-aminoimidazole-4-carboxamide ribonucleoside (AICAR) and metformin leads to an increase in oxidative metabolism as evidenced by enhanced lipid mobilisation (FA $\beta$-oxidation and lipolysis), decreased synthesis of PUFAs and increased oxygen consumption (Moreno-Arriola et al., 2016). Mice with the mutation in the AMPK y1 subunit, which leads to hepatic AMPK activation, fed HSD are characterised by reduced gluconeogenesis, FA synthesis and lipogenesis in the liver (Woods et al., 2017). Altogether, these results demonstrate that fat metabolism, important for the maintenance of energy homeostasis, is controlled by the coordinated action of neuronal signals, e.g. 5-HT and nutrient-sensing pathways such as AMPK and mTOR signalling in both C. elegans and mammals.

Lipid catabolism can also be regulated by the helixloop-helix transcription factor, HLH-11, an ortholog of the human transcription factor activating enhancer binding protein 4 (TFAP4) (Li et al., 2020). In well-fed nematodes, HLH-11 inhibits the transcription of lipid catabolism genes, whereas upon fasting, the HLH-11 protein is degraded, leading to an increase in the transcription of genes involved in lipid catabolism and reduction of the body fat content. Moreover, nutrient availability may regulate fat accumulation through lysosomal lipolysis mediated by two novel metabolic regulators, a MaX-like transcription factor MXL-3, and HLH-30, which is an ortholog of mammalian transcription factor EB (TFEB) (O'Rourke and Ruvkun, 2013). Upon food availability, MXL-3/MAX suppresses the expression of lysosomal genes, while HLH-30/TFEB remains inactive in the cyto- 
sol. Upon food deprivation, $m \times 1-3 \mathrm{mRNA}$ levels are downregulated, while hlh-30 transcription is increased and HLH-30 is enriched in the intestinal nuclei where it activates the transcription of genes encoding lysosomal lipases to mobilise lipid reservoirs and survive starvation. Interestingly, hlh-30 mutant worms die prematurely in fasting conditions, thus suggesting that HLH-30 is an essential metabolic regulator necessary for nematodes' survival during periods of starvation (O'Rourke and Ruvkun, 2013; Harvald et al., 2017). Fasting also down-regulates the expression of the FA desaturase fat-7, inhibits PUFA biosynthesis and increases FA $\beta$-oxidation (Van Gilst et al., 2005).

During prolonged fasting, in mammals, hepatic gluconeogenesis is downregulated through induction of the Kruppel-like factor 15 (KLF15). KLF15 interacts with the liver X receptor (LXR) to suppress Srebf1 transcription, resulting in downstream expression of genes encoding lipogenic enzymes as the primary adaptation mechanism to limited food availability (Takeuchi et al., 2016). In addition, overnight fasting leads to the activation of KLF15, which regulates gluconeogenesis and AA catabolism in the skeletal muscle (Gray et al., 2007). In murine BAT, fasting activates ALK7 which inhibits stress-induced activation of the lipolytic genes and AAdegrading enzymes through downstream stimulation of KLF15 (Marmol et al., 2020). Kruppel-like factor 3 (KLF-3) regulates fat storage in $C$. elegans through interaction with genes encoding enzymes regulating FA $\beta$-oxidation and de novo FA synthesis (Zhang et. al, 2011), indicating the conserved role of the Kruppel-like family of transcription factors in the regulation of fat metabolism.

Intermittent fasting (IF) is generally accepted as a safe and viable weight loss method for adults with obesity. The analysis of 27 clinical trials using IF in obesity treatment demonstrated $0.8 \%$ to $13 \%$ reduction in body weight, mostly due to the fat loss (Welton et al., 2020). A recent randomised human study with healthy individuals demonstrated that people consuming fasting mimicking diet (FMD), which is low in calories, sugars and protein but high in unsaturated FAs, for 5 consecutive days per month for 3 months have reduced body weight and total body fat and lower blood pressure (Wei et al., 2017). These findings indicate that prolonged fasting has beneficial effects on human health. Because starvation triggers a similar molecular response in nematodes and mammals, $C$. elegans seems to be a useful model organism to study long-term metabolic effects of dietary restriction.

\section{Changes in ambient temperature influence fat metabolism}

Mild changes in ambient temperature influence energy metabolism in rodent models of obesity. Mice reared at reduced ambient temperature from birth to weaning are protected against diet-induced obesity in adult life (Chabowska-Kita et al., 2015). Similarly, fat accumulation is markedly decreased in HFD-fed mice maintained at $17^{\circ} \mathrm{C}$ due to increased energy expenditure through nonshivering thermogenesis and enhanced metabolic efficiency (Ziętak et al., 2016). In mammals, cold stimulates the beta-3 adrenergic receptors ( $\beta 3$-AdRs) in the sympathetic nervous system (SNS). $\beta 3$-AdRs release norepinephrine (NE) and activate the UCP1-dependent thermogenesis in the BAT through cyclic adenosine monophosphate (cAMP)-driven activation of the protein kinase A (PKA) and p38 MAPK signalling pathways (Young et al., 1982; Cao et al., 2004). Murine and human adipocytes can also directly sense cold and thus activate thermogenesis independently of the canonical NE/ cAMP/PKA/p38 MAPK signalling pathway (Ye et al., 2013). During nonshivering thermogenesis, BAT dissipates chemical energy in the form of heat through utilisation of intracellular TAGs, circulating FFAs and glucose (Townsend and Tseng, 2014).

Although UCP1 ortholog is not present in $C$. elegans, worms express the uncoupling protein 4 (ucp-4), whose RNAi-mediated knockdown leads to increased fat accumulation and impaired IIS possibly due to oxidative stress (Ji et al., 2012). Unlike mammals, $C$. elegans contain lower levels of SFA, which allow worms to grow in cool environments (Tanaka et al., 1996; Brock et al., 2007). Cold temperature induces the expression of fat-7, which enables worms to adapt to decreased environmental temperature through changes in FA unsaturation (Murray et al., 2007). In both mammals and $C$. elegans, reduction of D9 desaturase activity leads to reduced fat accumulation (Ntambi et al., 2002; Hulver et al., 2005). Double mutant worms fat- 6 ; fat- 7 and fat-5; fat-7 accumulate high levels of SFA, which increases their cold sensitivity (Brock et al., 2007; Murray et al., 2007; Savory et al., 2011). Cold survival through influencing the activity of D9 desaturation is also regulated by phos- 
phoinositide-3 kinase (PI3K) (Savory et al., 2011), acylCoA dehydratase (acdh-11) (Ma et al., 2015), adiponectin receptor homolog ( paqr-2) (Svensson et al., 2011; Svensk et al., 2013), and immunoglobulin domain and leucine-rich repeat-containing protein 2 (iglr-2) (Svensk et al., 2016).

Cold exposure might stimulate fat loss through changes in the gut microbiota. In mice, thermoneutral ambient temperature $\left(29^{\circ} \mathrm{C}\right)$ increases the level of Firmicutes bacteria, e.g. Bacilli and Erysipelotrichaceae, associated with obesity (Turnbaugh et al., 2009), whereas low ambient temperature $\left(12^{\circ} \mathrm{C}\right)$ up-regulates the levels of Adlercreutzia and Desulfovibrio, which is a characteristic for the lean phenotype (Ziętak et al., 2016). Interestingly, changes in the intestinal microbiota are noticeable after 1 day at $12^{\circ} \mathrm{C}$ (Ziętak et al., 2016). In cold, the gut microbiota reduces fat content and improves insulin sensitivity through induction of UCP1dependent nonshivering thermogenesis, increases production of bile acids (BA) and enhances AMPK phosphorylation, which promotes energy expenditure and increases FA $\beta$-oxidation (Ziętak et al., 2016; Zietak and Kozak, 2016).

Similar to mammals, a temperature range of $15-25^{\circ} \mathrm{C}$ in $C$. elegans might change the composition of the gut microbiota (Berg et al., 2016). Low ambient temperature causes an increase in the level of Bacteroidetes, e.g. Sphingobacterium sp., and lowers the level of Agrobacterium sp. in the worm intestine (Berg et al., 2016). Low ambient temperature also stimulates production, release and response to 5-HT, which activates DAF$7 /$ TGF- $\beta$ and IIS, leading to a reduction in nematode body fat content (Sze et al., 2000). At high ambient temperature, DAF-7 expression induces dauer formation in worms (You et al., 2008). Another factor that regulates fat metabolism in $C$. elegans, REGE-1, is required for worm survival during cold adaptation (Habacher et al., 2016). Under standard temperature conditions, REGE-1 promotes fat accumulation by degrading the transcription factor ETS-4, which regulates the expression of fat catabolism and immunity genes (Habacher et al., 2016). Mutation in the rege-1 gene causes increased ETS-4 expression, which stimulates fat loss and death in worms maintained at low ambient temperature.

In the past few years, several studies have demonstrated that cold recruits and increases thermogenic activity of BAT, leading to enhanced oxidative metabo- lism and energy expenditure in humans (Ouellet et al., 2012; Muzik et al., 2013, Yoneshiro et al; 2013). Although activation of the UCP1-dependent nonshivering thermogenesis leads to a significant decrease in the body fat mass in healthy individuals (Yoneshiro et al., 2013), several clinical trials have been or will be testing the efficacy of long-term mild cold treatment and nutrient administration on recruitment and activity of BAT in individuals with obesity (retrieved from Clinical Trials.gov).

Low ambient temperature can stimulate fat utilisation through different molecular mechanisms and thus seems to be a promising approach that could be used to prevent and treat obesity. Although molecular mechanisms triggered by cold in $C$. elegans differ from the response observed in mammals, both mammals and nematodes adapt to cool environments through modulation of lipid metabolism and changes in the composition of the gut microbiota to provide energy necessary for their survival.

\section{Summary}

Abnormal metabolic regulation due to inborn errors as well as changes in modern diet and lifestyle have enormous health consequences. Unlimited access to food contributes to the development of metabolic disorders, e.g. obesity, T2D and cardiovascular diseases. Although appropriate dietary modifications can control some of the metabolic defects, the relative efficiency of different types of diets used to battle obesity and T2D remain controversial. Long-term use of medications in obesity treatment has modest effectiveness and exerts many side effects. Therefore, it is important to have a deeper understanding of the existing molecular pathways and search for novel regulators of fat accumulation.

Despite differences in the physiology between species, available model organisms such as rodents and nematodes are useful to explain the basic principles of fat regulation. In most cases, genetically induced obesity in humans develops from the accumulation of multiple mutations, resulting in abnormal food absorption, energy metabolism or food intake (WHO, 1998). In C. elegans, over 400 genetic mutations cause abnormal fat metabolism, leading to decreased fat accumulation or enhanced fat utilisation (Ashrafi et al., 2003). Although mechanisms regulating fat storage and development of obesity in mammals are complex, many known signalling pathways regulating glucose and fat metabolism have their 
Table 1. Factors involved in the metabolic regulation in $C$. elegans and their mammalian orthologs

\begin{tabular}{|c|c|c|c|c|}
\hline C. elegans gene & Human ortholog & Protein activity & Function in C. elegans & Reference \\
\hline $\begin{array}{l}\text { aak-1, aak-2 } \\
\text { (AMP-activated protein kinases) }\end{array}$ & $\begin{array}{l}\text { PRKAA1, PRKAA2 (protein kinase } \\
\text { AMP-activated catalytic subunits } \alpha 1 \text { and } \alpha 2 \text { ) }\end{array}$ & $\begin{array}{l}\text { AMP-activated } \\
\text { protein kinases }\end{array}$ & $\begin{array}{l}\text { FA } \beta \text {-oxidation and lipolysis, } \\
\text { decreased synthesis of PUFAs } \\
\text { and increased oxygen consumption }\end{array}$ & $\begin{array}{l}\text { Apfeld et al., 2004; } \\
\text { Moreno-Arriola et al., } 2016\end{array}$ \\
\hline acs-4 (acyl CoA synthetase family) & $\begin{array}{l}\text { ACSL3 (acyl-CoA synthetase long chain } \\
\text { family member } 3 \text { ) }\end{array}$ & synthetase & promotes LD biogenesis at the ER & Vrablik et al., 2015 \\
\hline atx-2(ataxin 2) & $A T X N 2($ ataxin 2) & $\begin{array}{l}\text { protein } \\
\text { with an unknown function }\end{array}$ & $\begin{array}{l}\text { negatively regulates } \\
\text { the mTOR signalling pathway }\end{array}$ & Bar et al., 2016 \\
\hline$c p l-1$ (cathepsin L-like protease) & $\begin{array}{l}\text { CTSL1 (cathepsin L1), } \\
\text { CTSB (cathepsin B) }\end{array}$ & protease & regulates fat accumulation & Lin et al., 2019a \\
\hline daf-2 (abnormal dauer formation) & $I N S R$ (insulin receptor) & receptor tyrosine kinase & $\begin{array}{l}\text { signal transduction } \\
\text { in the IIS pathway }\end{array}$ & Kimura et al., 1997 \\
\hline $\begin{array}{l}\text { daf-16 } \\
\text { (abnormal dauer formation } 16 \text { ) }\end{array}$ & FOXO (forkhead box) & transcription factor & $\begin{array}{l}\text { regulates the expression of genes } \\
\text { involved in fat and glucose metabolism }\end{array}$ & Kimura et al., 1997 \\
\hline $\begin{array}{l}\text { dgat-2 } \\
\text { (diacylglycerol O-acyltransferase 2) }\end{array}$ & DGAT2 (diacylglycerol transferase 2) & transferase & converts DAGs into TAGs & $\begin{array}{l}\text { Cao et al., 2019; } \\
\text { Xu et al., 2012a }\end{array}$ \\
\hline elo-1 (fatty acid elongase 1 ) & $\begin{array}{l}E L O V L 3, E L O V L 6 \\
\text { (fatty acid elongase } 3 \text { and } 6 \text { ) }\end{array}$ & elongase & biosynthesis of long-chain PUFA & Watts and Browse, 2002 \\
\hline fat -3 (fatty acid desaturase 3 ) & $\begin{array}{l}F A D S 1, F A D S 2 \\
\text { (fatty acid desaturase } 1 \text { and } 2 \text { ) }\end{array}$ & delta- 6 desaturase & biosynthesis of long-chain PUFA & $\begin{array}{l}\text { Watts and Browse, 2002; } \\
\text { Wallis et al., } 2002\end{array}$ \\
\hline fat -4 (fatty acid desaturase 4 ) & $\begin{array}{l}\text { FADS1, FADS2, FADS3 } \\
\text { (fatty acid desaturase } 1,2 \text { and } 3 \text { ) }\end{array}$ & delta- 5 desaturase & biosynthesis of long-chain PUFA & $\begin{array}{l}\text { Watts and Browse, 2002; } \\
\text { Wallis et al., } 2002\end{array}$ \\
\hline
\end{tabular}


Table 1 cont.

\begin{tabular}{|c|c|c|c|c|}
\hline C. elegans gene & Human ortholog & Protein activity & Function in C. elegans & Reference \\
\hline $\begin{array}{l}\text { fat }-5 \text {, (fatty acid desaturase } 5) \\
\text { fat- } 6 \text { (fatty acid desaturase } 6) \\
\text { fat }-7 \text { (fatty acid desaturase } 7 \text { ) }\end{array}$ & $S C D 1, S C D 5$ (stearoyl-CoA desaturase) & delta-9 desaturase & biosynthesis MUFAs from SFAs & Brock et al., 2007 \\
\hline$H L H-11$ & $\begin{array}{l}\text { TFAP4 (transcription factor activating } \\
\text { enhancer binding protein } 4 \text { ) }\end{array}$ & transcription factor & $\begin{array}{l}\text { inhibits transcription } \\
\text { of lipid catabolism genes }\end{array}$ & Li et al., 2020 \\
\hline$H L H-30$ & $T F E B$ (transcription factor EB) & transcription factor & $\begin{array}{l}\text { activates transcription of genes } \\
\text { encoding lysosomal lipases }\end{array}$ & $\begin{array}{l}\text { O’Rourke and Ruvkun, 2013; } \\
\text { Harvald et al., } 2017\end{array}$ \\
\hline lipl-5 & $\begin{array}{l}L I P A \text { (lipase A, lysosomal acid type), } \\
L I P F \text { (lipase F, gastric type), } \\
\text { and } L I P M \text { (lipase family member M) }\end{array}$ & lipase & converts TAGs to FFAs and glycerol & Aranaz et al., 2020 \\
\hline $\begin{array}{l}\text { nhr- } 49 \\
\text { (nuclear hormone receptor) }\end{array}$ & $\begin{array}{l}H N F 4 A, H N F 4 G \text { (hepatocyte nuclear factor } \\
4 \text { alpha and } 4 \text { gamma) }\end{array}$ & nuclear hormone receptor & $\begin{array}{l}\text { promotes expression } \\
\text { of delta-9 FA desaturase gene }\end{array}$ & Arda et al., 2010 \\
\hline pept-1 (peptide transporter 1 ) & $\begin{array}{l}\text { SLC15A1 } \\
\text { (solute carrier family } 15 \text { member } 1 \text { ) }\end{array}$ & transporter & $\begin{array}{l}\text { intestinal transport of di- } \\
\text { and tripeptides, FA flip-flop }\end{array}$ & $\begin{array}{l}\text { Spanier et al., 2009; } \\
\text { Benner et al., 2011; } \\
\text { Brooks et al., 2009 }\end{array}$ \\
\hline rege-1 & $\begin{array}{l}Z c 3 h 12 a \\
\text { (zinc finger CCCH-Type Containing 12A) }\end{array}$ & endoribonuclease & $\begin{array}{l}\text { inhibits lipid catabolism } \\
\text { due to ets-4 mRNA decay }\end{array}$ & $\begin{array}{l}\text { Xu et al., 2012; } \\
\text { Habacher et al., 2016; } \\
\text { Habacher and Ciosk, } 2017\end{array}$ \\
\hline $\begin{array}{l}\text { sbp-1 } \\
\text { (sterol regulatory element binding } 1)\end{array}$ & $\begin{array}{l}\text { SREBF2 (sterol regulatory element binding } \\
\text { transcription factor } 2 \text { ) }\end{array}$ & transcription factor & promotes lipid biosynthesis & $\begin{array}{l}\text { McKay et al., 2003; } \\
\text { Nomura et al., } 2010\end{array}$ \\
\hline seip-1 (seipin 1) & $\begin{array}{l}\text { BSCL2 (Berardinelli-Seip congenital } \\
\text { lipodystrophy 2) }\end{array}$ & $\begin{array}{l}\text { transmembrane protein } \\
\text { located in the ER }\end{array}$ & promotes LD formation & Cao et al., 2019 \\
\hline tub-1 (tubby 1 ) & $T U B$ (tubby) & transcription factor & $\begin{array}{l}\text { modulates processing } \\
\text { and vesicular transport }\end{array}$ & DiTirro et al., 2019 \\
\hline
\end{tabular}


counterparts in $C$. elegans (as summarised in Table 1) (Sze et al., 2000; Jia, 2004; Perez and Van Gilst, 2008; Moreno-Arriola et al., 2016).

Changes in lifestyle, including increased physical activity and modification of eating habits, along with appropriate pharmacology enhance the efficiency of obesity interventions. However, the need for an effective and safe therapeutic approach for individuals with morbid obesity who are unable to exercise still exists. To maintain energy homeostasis and prolong survival, both mammals and nematodes adapt to constant changes in environmental conditions such as the type of diet, nutrient availability and ambient temperature. Natural bioactive compounds enriched in diet modulate metabolism and thus might be used to improve human health. Flavones, phenolic compounds and phenolic acids affect lipid metabolism in both $C$. elegans (Aranaz et al., 2020) and mammals (Zhang et al., 2016; Shen et al., 2019). Therefore, $C$. elegans might be used as a model organism to determine metabolic effects, exclude potential toxicity and investigate molecular mechanisms that mediate antiobesity effect of different bioactive compounds. Although the composition of the human gut microbiota is more complex as compared to that of $C$. elegans, bacterial species from Firmicutes and Bacteroides phyla, which are sensitive to environmental changes such as diet and ambient temperature, are found in the intestine from nematodes and mammals (Berg et al., 2016; Ziętak et al., 2016; Jie et al., 2021). Moreover, environmental cues strongly contribute to changes in adiposity. Despite differences in molecular mechanisms triggered by the low ambient temperature, the main metabolic effects of cold stimulation, such as increased fat utilisation, are observed in both $C$. elegans (Brock et al., 2007) and mammals (Yoneshiro et al., 2013; Ziętak et al., 2016).

In conclusion, relatively short lifespan, reproduction cycle and large brood size make $C$. elegans a useful model organism for research of many human diseases that lack an effective and safe treatment. The availability of a variety of cellular, molecular, genetic and behavioural analyses and conservation of key fat-regulatory pathways between nematodes and humans promote $C$. elegans as an attractive tool in obesity research.

\section{References}

Abarca-Gómez L., Abdeen Z.A., Hamid Z.A., Abu-Rmeileh N.M., Acosta-Cazares B., Acuin C. et al. (2017) Worldwide trends in body-mass index, underweight, overweight, and obesity from 1975 to 2016: a pooled analysis of $2416 \mathrm{popu-}$ lation-based measurement studies in 128.9 million children, adolescents, and adults. The Lancet 390(10113): 2627-2642.

ALJohani A.M., Syed D.N., Ntambi J.M. (2017) Insights into stearoyl-CoA desaturase-1 regulation of systemic metabolism. Trends Endocrinol. Metabol. 28(12): 831-842.

Aoun A., Darwish F., Hamod N. (2020) The influence of the gut microbiome on obesity in adults and the role of probiotics, prebiotics, and synbiotics for weight loss. Prev. Nutr. Food Sci., 25(2), 113-123.

Apfeld J., O'Connor G., McDonagh T., DiStefano P.S., Curtis R. (2004) The AMP-activated protein kinase $A A K-2$ links energy levels and insulin-like signals to lifespan in C. elegans. Genes Develop. 18(24): 3004-3009.

Aranaz P., Navarro-Herrera D., Romo-Hualde A., Zabala M., López-Yoldi M., González-Ferrero C., Gil A.G., Martinez J.A., Vizmanos J.L., Milagro F.I., González-Navarro C.J. (2019a) Broccoli extract improves high fat diet-induced obesity, hepatic steatosis and glucose intolerance in Wistar rats. J. Func. Foods 59: 319-328.

Aranaz P., Navarro-Herrera D., Zabala M., Miguéliz I., RomoHualde A., López-Yoldi M., Martínez J.A., Vizmanos J.L., Milagro F.I., González-Navarro C.J. (2019) Phenolic compounds inhibit 3T3-L1 adipogenesis depending on the stage of differentiation and their binding affinity to PPAR. Molecules 24(6): 1045.

Aranaz P., Navarro-Herrera D., Zabala M., Romo-Hualde A., López-Yoldi M., Vizmanos J.L., Milagro F.I., González-Navarro C.J. (2020) Phenolic compounds reduce the fat content in Caenorhabditis elegans by affecting lipogenesis, lipolysis, and different stress responses. Pharmaceuticals 13(11): 355.

Arcidiacono B., Chiefari E., Foryst-Ludwig A., Curro G., Navarra G., Brunetti F.S., Mirabelli M., Corigliano D.M., Kintscher U., Britti D. et al. (2020) Obesity-related hypoxia via miR-128 decreases insulin-receptor expression in human and mouse adipose tissue promoting systemic insulin resistance. EBioMedicine 59: 102912.

Arda H.E., Taubert S., MacNeil L.T., Conine C.C., Tsuda B., Van Gilst M., Sequerra R., Doucette-Stamm L., Yamamoto K.R., Walhout A.J.M. (2010) Functional modularity of nuclear hormone receptors in a Caenorhabditis elegans metabolic gene regulatory network. Mol. Syst. Biol. 6: 367.

Ashrafi K., Chang F.Y., Watts J.L., Fraser A.G., Kamath R.S., Ahringer J., Ruvkun G. (2003) Genome-wide RNAi analysis of Caenorhabditis elegans fat regulatory genes. Nature 421(6920): 268-272.

Ashrafi K. (2007) Obesity and the regulation of fat metabolism. Wormbook 1-20. http://doi.org/10.1895/wormbook. 1.130.1; http://www.wormbook.org.

Avery L., Horvitz H.R. (1990) Effects of starvation and neuroactive drugs on feeding in Caenorhabditis elegans. J. Exp. Zool. 253(3): 263-270.

Avery L., Shtonda B.B. (2003) Food transport in the C. elegans pharynx. J. Exp. Biol. 206(14): 2441-2457. 
Backhed F., Ding H., Wang T., Hooper L.V., Koh G.Y., Nagy A., Semenkovich C.F., Gordon J.I. (2004) The gut microbiota as an environmental factor that regulates fat storage. Proc. Natl. Acad. Sci. USA 101(44): 15718-15723.

Bar D.Z., Charar C., Dorfman J., Yadid T., Tafforeau L., Lafontaine D.L.J., Gruenbaum Y. (2016) Cell size and fat content of dietary-restricted Caenorhabditis elegans are regulated by $A T X-2$, an $m T O R$ repressor. Proc. Natl Acad. Sci. USA 113(32): E4620-E4629.

Bauer M., Hamm A.C., Bonaus M., Jacob A., Jaekel J., Schorle H., Pankratz M.J., Katzenberger J.D. (2004) Starvation response in mouse liver shows strong correlation with life-spanprolonging processes. Physiol. Genomics 17(2): 230-244.

Benner J., Daniel H., Spanier B. (2011) A glutathione peroxidase, intracellular peptidases and the TOR complexes regulate peptide transporter PEPT-1 in C. elegans. PLoS One 6(9): e25624.

Berg M., Stenuit B., Ho J., Wang A., Parke C., Knight M., Alvarez-Cohen L., Shapira M. (2016) Assembly of the Caenorhabditis elegans gut microbiota from diverse soil microbial environments. ISME J. 10(8): 1998-2009.

Boggon T.J. (1999) Implication of tubby proteins as transcription factors by structure-based functional analysis. Science 286(5447): 2119-2125.

Boucher J., Softic S., El Ouaamari A., Krumpoch M.T., Kleinridders A., Kulkarni R.N., O’Neill B.T., Kahn C.R. (2016) Differential roles of insulin and IGF-1 receptors in adipose tissue development and function. Diabetes 65(8): 2201-2213.

Brandsch M. (2013) Drug transport via the intestinal peptide transporter PepT1. Curr. Opin. Pharmacol. 13(6): 881-887.

Brock T. J., Browse J., Watts J.L. (2006) Genetic regulation of unsaturated fatty acid composition in $C$. elegans. PLoS Genet. 2(7): e108.

Brock T.J., Browse J., Watts J.L. (2007) Fatty acid desaturation and the regulation of adiposity in Caenorhabditis elegans. Genetics 176(2): 865-875.

Brooks K.K., Liang B., Watts J.L. (2009) The influence of bacterial diet on fat storage in C. elegans. PLoS One 4(10): e7545.

Bugianesi E., McCullough A.J., Marchesini G. (2005) Insulin resistance: a metabolic pathway to chronic liver disease. Hepatology 42(5): 987-1000.

Bulger D.A., Fukushige T., Yun S., Semple R.K., Hanover J.A., Krause M.W. (2016) Caenorhabditis elegans DAF-2 as a model for human insulin receptoropathies. Genes Genom. Genet. 7(1): 257-268.

Buyse M., Berlioz F., Guilmeau S., Tsocas A., Voisin T., Péranzi G., Merlin D., Laburthe M., Lewin M.J.M., Rozé C., Bado A. (2001) PepT1-mediated epithelial transport of dipeptides and cephalexin is enhanced by luminal leptin in the small intestine. J. Clin. Invest. 108(10): 1483-1494.

Cakir O., Ucarli C., Tarhan C., Pekmez M., Turgut-Kara N. (2019) Nutritional and health benefits of legumes and their distinctive genomic properties. Food Sci. Technol. Campinas 39(1): 1-12.
Cao W., Daniel K.W., Robidoux J., Puigserver P., Medvedev A.V., Bai X., Floering L.M., Spiegelman B.M., Collins S. (2004) p38 mitogen-activated protein kinase is the central regulator of cyclic AMP-dependent transcription of the brown fat uncoupling protein 1 gene. Mol. Cel. Biol. 24(7): 3057-3067.

Cao Z., Hao Y., Fung C.W., Lee Y.Y., Wang P., Li X., Xie K., Lam W.J., Qiu Y., Tang B.Z. et al. (2019) Dietary fatty acids promote lipid droplet diversity through seipin enrichment in an ER subdomain. Nature Commun. 10(1): 2902.

Carroll L., Voisey J., Van Daal A. (2004) Mouse models of obesity. Clin. Dermatol. 22(4): 345-349.

Chabowska-Kita A., Trabczynska A., Korytko A., Kaczmarek M.M., Kozak L.P. (2015) Low ambient temperature during early postnatal development fails to cause a permanent induction of brown adipocytes. FASEB J. 29(8): 3238-3252.

Chan E.W., He Y., Chui C.S.L., Wong A.Y.S., Lau W.C.Y., Wong I.C.K. (2013) Efficacy and safety of lorcaserin in obese adults: a meta-analysis of 1-year randomized controlled trials (RCTS) and narrative review on short-term RCTs. Obesity Treat. 14(5): 383-392.

Chiang S.-H., MacDougald O.A. (2003) Will fatty worms help cure human obesity? Trends Genet. 19(10): 523-525.

Choi W.H., Son H.J., Jang Y.J., Ahn J., Jung C.H., Ha T.Y. (2017) Apigenin ameliorates the obesity-induced skeletal muscle atrophy by attenuating mitochondrial dysfunction in the muscle of obese mice. Mol. Nutr. Food Res. 61(12): 1700218.

ClinicalTrials.gov, https://clinicaltrials.gov

Cota D., Matter E.K., Woods S.C., Seeley R.J. (2008) The role of hypothalamic mammalian target of rapamycin complex 1 signaling in diet-induced obesity. J. Neurosci. 28(28): 7202-7208.

Czech M.P. (2017) Insulin action and resistance in obesity and type 2 diabetes. Nat. Med. 23(7): 804-814.

David L.A., Maurice C.F., Carmody R.N., Gootenberg D.B., Button J.E., Wolfe B.E., Ling A.V., Devlin A.S., Varma Y., Fischbach M.A., Biddinger S.B., Dutton R.J., Turnbaugh P.J. (2014) Diet rapidly and reproducibly alters the human gut microbiome. Nature 505(7484): 559-563.

Davis C.D. (2016) The gut microbiome and its role in obesity. Nutr. Today 51(4): 167-174.

De Filippo C., Cavalieri D., Di Paola M., Ramazzotti M., Poullet J.B., Massart S., Collini S., Pieraccini G., Lionetti P. (2010) Impact of diet in shaping gut microbiota revealed by a comparative study in children from Europe and rural Africa. Proc. Natl. Acad. Sci USA 107(33): 14691-14696.

De Ligt M., Timmers S., Schrauwen P. (2015) Resveratrol and obesity: can resveratrol relieve metabolic disturbances? Biochim. Biophys. Acta: Mol. Basis Dis. 1852(6): 1137-1144.

Dirksen P., Marsh S.A, Braker I., Heitland N., Wagner S., Nakad R., Mader S., Petersen C., Kowallik V., Rosenstiel P. et al. (2016) The native microbiome of the nematode Caenorhabditis elegans: gateway to a new host-microbiome model. BMC Biol. 14(1): 38. 
DiTirro D., Philbrook A., Rubino K., Sengupta P. (2019) The Caenorhabditis elegans Tubby homolog dynamically modulates olfactory cilia membrane morphogenesis and phospholipid composition. eLife 1(8): 48789.

Dobrzyn P., Dobrzyn A., Miyazaki M., Cohen P., Asilmaz E., Hardie D.G., Friedman J.M., Ntambi J.M. (2004) StearoylCoA desaturase 1 deficiency increases fatty acid oxidation by activating AMP-activated protein kinase in liver. Proc. Natl. Acad. Sci USA 101(17): 6409-6414.

Dranse H.J., Waise T.M.Z., Hamr S.C., Bauer P.V., Abraham M.A., Rasmussen B.A., Lam T.K.T. (2018) Physiological and therapeutic regulation of glucose homeostasis by upper small intestinal PepT1-mediated protein sensing. Nature Commun. 9(1): 1118.

Dulloo A.G., Duret C., Rohrer D., Girardier L., Mensi N., Fathi M., Chantre P., Vandermander J. (1999) Efficacy of a green tea extract rich in catechin polyphenols and caffeine in increasing 24-h energy expenditure and fat oxidation in humans. Am. J. Clin. Nutr. 70(6): 1040-1045.

El Khoury D., Cuda C., Luhovyy B.L., Anderson G.H. (2012) Beta glucan: health benefits in obesity and metabolic syndrome. J. Nutr. Metab. 2012: 1-28.

Finley J.W., Sandlin C., Holliday D.L., Keenan M.J., Prinyawiwatkul W., Zheng J. (2013) Legumes reduced intestinal fat deposition in the Caenorhabditis elegans model system. J. Func. Foods 5(3): 1487-1493.

Frank D.N., St. Amand A.L., Feldman R.A., Boedeker E.C., Harpaz N., Pace N.R. (2007) Molecular-phylogenetic characterization of microbial community imbalances in human inflammatory bowel diseases. Proc. Natl. Acad. Sci USA 104(34): 13780-13785.

Funicello M., Novelli M., Ragni M., Vottari T., Cocuzza C., Soriano-Lopez J., Chiellini C., Boschi F., Marzola P., Masiello P. et al. (2007) Cathepsin K null mice show reduced adiposity during the rapid accumulation of fat stores. PLoS One 2(8): e683.

Gao Z., Yin J., Zhang J., Ward R.E., Martin R.J., Lefevre M. et al. (2009) Butyrate improves insulin sensitivity and increases energy expenditure in mice. Diabetes 58(7): 1509-1517.

Gao C., Gao Z., Greenway F.L., Burton J.H., Johnson W.D., Keenan M.J., Enright F.M., Martin R.J., Chu Y., Zheng J. (2015) Oat consumption reduced intestinal fat deposition and improved health span in Caenorhabditis elegans model. Nutr. Res. 35(9): 834-843.

Gao A.W., Chatzispyrou I.A., Kamble R., Liu Y.J., Herzog K., Smith R.L., van Lenthe H., Vervaart M.A.T., van Cruchten A., Luyf A.C. et al. (2017) A sensitive mass spectrometry platform identifies metabolic changes of life history traits in C. elegans. Sci. Rep. 7(1): 2408.

Garcia A.M., Ladage M.L., Dumesnil D.R., Zaman K., Shulaev V., Azad R.K., Padilla P.A. (2015) Glucose induces sensitivity to oxygen deprivation and modulates insulin/IGF-1 signaling and lipid biosynthesis in Caenorhabditis elegans. Genetics 200(1): 167-184.
Garfield A.S., Heisler L.K. (2009) Pharmacological targeting of the serotonergic system for the treatment of obesity. J. Physiol. 587(1): 49-60.

Gray J.M., Hill J.J., Bargmann C.I. (2005) A circuit for navigation in Caenorhabditis elegans. Proc. Natl Acad. Sci. USA 102(9): 3184-3191.

Gray S., Wang B., Orihuela Y., Hong E.G., Fisch S., Haldar S., Cline G.W., Kim J.K., Peroni O.D., Kahn B.B., Jain M.K. (2007) Regulation of gluconeogenesis by Kruppel-like factor 15. Cell Metab. 5(4): 305-312.

Greer E.L., Dowlatshahi D., Banko M.R., Villen J., Hoang K., Blanchard D., Gygi S.P., Brunet A. (2007) An AMPKFOXO pathway mediates longevity induced by a novel method of dietary restriction in C. elegans. Curr. Biol. 17(19): 1646-1656.

Greer E.R., Perez C.L., Van Gilst M.R., Lee B.H., Ashrafi K. (2008) Neural and molecular dissection of a C. elegans sensory circuit that regulates fat and feeding. Cell. Metab. 8(2): 118-131.

Grover J.K., Yadav S.P. (2004) Pharmacological actions and potential uses of Momordica charantia: a review. J. Ethnopharmacol. 93(1): 123-132.

Haase C.L., Eriksen K.T., Lopes S., Satylganova A., Schnecke V., McEwan P. (2021) Body mass index and risk of obesity related conditions in a cohort of 2.9 million people: evidence from a UK primary care database. Obes. Sci. Pract. 7(2): 137-147.

Habacher C., Yanwu G., Venz R., Kumari P., Neagu A., Gaidatzis D., Harvald E.B., Færgeman N.J., Gut H., Ciosk R. (2016) Ribonuclease-mediated control of body fat. Develop. Cell 39(3): 359-369.

Habacher C., Ciosk R. (2017) ZC3H12A/MCPIP1/Regnase-1related endonucleases: an evolutionary perspective on molecular mechanisms and biological functions. Bioessays 39(9): 1700051.

Hardie D.G., Ross F.A., Hawley S.A. (2012) AMPK: a nutrient and energy sensor that maintains energy homeostasis. Mol. Cell Biol. 13(4): 251-262.

Harvald E.B., Sprenger R.R., Dall K.B., Ejsing C.S., Nielsen R., Mandrup S., Murillo A.B., Larance M., Gartner A., Lamond A.I., Faergeman N.J. (2017) Multi-omics analyses of starvation responses reveal a central role for lipoprotein metabolism in acute starvation survival in C. elegans. Cell Syst. 5(1): 38-52.

Hayhurst G.P., Lee Y.H., Lambert G., Ward J.M., Gonzalez F.J. (2001) Hepatocyte nuclear factor $4 a$ (nuclear receptor 2A1) is essential for maintenance of hepatic gene expression and lipid homeostasis. Mol. Cell Biol. 21(4): 1393-1403.

Hellerer T., Axang C., Brackmann C., Hillertz P., Pilon M., Enejder A. (2007) Monitoring of lipid storage in Caenorhabditis elegans using coherent anti-Stokes Raman scattering (CARS) microscopy. Proc. Natl Acad. Sci. USA 104(37): 14658-14663. 
Hindlet P., Bado A., Kamenicky P., Delomenie C., Bourasset F., Nazaret C., Farinotti R., Buyse M. (2009) Reduced intestinal absorption of dipeptides via PepT1 in mice with diet-induced obesity is Associated with leptin receptor down-regulation. J. Biol. Chem. 284(11): 6801-6808.

Hooper L.V., Wong M.H., Thelin A., Hansson L., Falk P.G., Gordon J.I. (2001) Molecular analysis of commensal hostmicrobial relationships in the intestine. Science 291(5505): 881-884.

Huang K.-W., Reebye V., Czysz K., Ciriello S., Dorman S., Reccia I., Lai H.-S., Peng L., Kostomitsopoulos N., Nicholls J. et al. (2020) Liver activation of hepatocellular nuclear factor-4a by small activating $R N A$ rescues dyslipidemia and improves metabolic profile. Mol. Ther.: Nucl. Acids 19: 361-370.

Hulver M.W., Berggren J.R., Carper M.J., Miyazaki M., Ntambi J.M., Hoffman E.P., Thyfault J.P., Stevens R., Dohm G.L., Houmard J.A., Muoio D.M. (2005) Elevated stearoyl-CoA desaturase-1 expression in skeletal muscle contributes to abnormal fatty acid partitioning in obese humans. Cell Metab. 2(4): 251-261.

Ikeda A., Zheng Q.Y., Rosenstiel P., Maddatu T., Zuberi A.R., Roopenian D.C., North M.A., Naggert J.K., Johnson K.R., Nishina P.M. (1999) Genetic modification of hearing in tubby mice: evidence for the existence of a major gene (moth1) which protects tubby mice from hearing loss. Human Mol. Gen. 8(9): 1761-1767.

Imamura H., Nagayama D., Ishihara N., Tanaka S., Watanabe R., Watanabe Y., Satoa Y., Yamaguchia T., Bana N., Kawanaa H. et al. (2017) Resveratrol attenuates triglyceride accumulation associated with upregulation of Sirt1 and lipoprotein lipase in 3T3-L1 adipocytes. Mol. Gene. Metab. Rep. 12: 44-50.

Jacobson S.G., Cideciyan A.V., Huang W.C., Sumaroka A., Roman A.J., Schwartz S.B., Luo X., Sheplock R., Dauber J.M., Swider M., Stone E.M. (2014) TULP1 mutations causing early-onset retinal degeneration: preserved but insensitive macular cones. Invest. Ophthalmol. Vis. Sci. 55(8): 5354-5364.

Jain T., Sharma P., Are A.C., Vickers S.M., Dudeja V. (2021) New insights into the cancer-microbiome-immune axis: decrypting a decade of discoveries. Front. Immunol. 12: 622064.

Jandhyala S.M., Talukdar R., Subramanyam C., Vuyyuru H., Sasikala M., Reddy D.N. (2015) Role of the normal gut microbiota. World J. Gastroenterol. 21(29): 8787-8803.

Ji C., Guo W., Zhang M., Lu X., Ni Y., Guo X. (2012) Caenorhabditis elegans ucp-4 regulates fat metabolism: Suppression of ucp-4 expression induced obese phenotype and caused impairment of insulin like pathway. Gene 491(2): $158-164$.

Jia K. (2004) The TOR pathway interacts with the insulin signaling pathway to regulate $C$. elegans larval development, metabolism and life span. Development 131(16): 3897-3906.

Jie Z., Yu X., Liu Y., Sun L., Chen P., Ding Q., Gao Y., Zhang X., Yu M., Liu Y., Zhang Y., Kristiansen K., Jia H., Brix S.,
Cai K. (2021) The baseline gut microbiota directs dietinginduced weight loss trajectories. Gastroenterology 160(6): 2029-2042.

Jones S.E., Whitehead K., Saulnier D., Thomas C.M., Versalovic J., Britton R.A. (2011) Cyclopropane fatty acid synthase mutants of probiotic human-derived Lactobacillus reuteri are defective in TNF inhibition. Gut Microbes 2(2): 69-79.

Jung Y., Park J., Kim H.-L., Sim J.-E., Youn D.-H., Kang J., Lim S., Jeong M.-Y., Yang W.M., Lee S.G. et al. (2018) Vanillic acid attenuates obesity via activation of the AMPK pathway and thermogenic factors in vivo and in vitro. FASEB J. 32(3): 1388-1402.

Kahn-Kirby A.H., Dantzker J.L.M., Apicella A.J., Schafer W.R., Browse J., Bargmann C.I., Watts J.L. (2004) Specific polyunsaturated fatty acids drive TRPV-dependent sensory signaling in vivo. Cell 119(6): 889-900.

Kang S.I., Shin H.-S., Kim H.M., Hong Y.-S., Yoon S.-A, Kang S.-W., Kim J.-H., Ko H.-C., Kim S.-J. (2012) Anti-obesity properties of a Sasa quelpaertensis extract in high-fat dietinduced obese mice. Biosci. Biotechnol. Biochem. 76(4): 755-761.

Ke W., Saba J.A., Yao C.-H., Hilzendeger M.A., DrangowskaWay A., Joshi C., Mony V.K., Benjamin S.B., Zhang S., Locasale J. et al. (2020) Dietary serine-microbiota interaction enhances chemotherapeutic toxicity without altering drug conversion. Nature Commun. 11(1): 2587.

Keenan M.J., Zhou J., McCutcheon K.L., Raggio A.M., Bateman H.G., Todd E. et al. (2006) Effects of resistant starch, a non-digestible fermentable fiber, on reducing body fat. Obesity 14(9): 1523-1534.

Kennett G.A., Dourish C.T., Curzon G. (1987) 5-HTIB agonists induce anorexia at a postsynaptic site. Eur. J. Pharmacol. 141(3): 429-435.

Kiehl T.-R., Nechiporuk A., Figueroa K.P., Keating M.T., Huynh D.P., Pulst S.-M. (2006) Generation and characterization of Sca2 (ataxin-2) knockout mice. Biochem. Biophys. Res. Commun. 339(1): 17-24.

Kim J.K., Zisman A., Fillmore J.J., Peroni O.D., Kotani K., Perret P., Zong H., Dong J., Kahn C.R., Kahn B.B., Shulman G.I. (2001) Glucose toxicity and the development of diabetes in mice with muscle-specific inactivation of GLUT4. J. Clin. Invest. 108(1): 153-160.

Kim S.M., Lun M., Wang M., Senyo S.E., Guillermier C., Patwari P., Steinhauser M.L. (2014) Loss of white adipose hyperplastic potential is associated with enhanced susceptibility to insulin resistance. Cell Metabol. 20(6): 1049-1058.

Kimura K.D., Tissenbaum H.A., Liu Y., Ruvkun G. (1997) daf2, an insulin receptor-like gene that regulates longevity and diapause in Caenorhabditis elegans. Science 277(5328): 942-946.

Kingsley S.F., Seo Y., Allen C., Ghanta K.S., Finkel S., Tissenbaum H.A. (2021) Bacterial processing of glucose modulates C. elegans lifespan and healthspan. Sci. Rep. 11(1): 5931. 
Kissoyan K.A.B., Drechsler M., Stange E.-L., Zimmermann J., Kaleta C., Bode H.B., Dierking K. (2019) Natural C. elegans microbiota protects against infection via production of a cyclic lipopeptide of the viscosin group. Curr. Biol. 29(6): 1030-1037.

Kleyn P.W., Fan W., Kovats S.G., Lee J.J., Pulido J.C., Wu Y., Berkemeier L.R., Misumi D.J., Holmgren L., Charlat O. et al. (1996) Identification and characterization of the mouse obesity gene tubby: a member of a novel gene family. Cell 85(2): 281-290.

Kolodziejczak D., Spanier B., Pais R., Kraiczy J., Stelzl T., Gedrich K., Scherling C., Zietek T., Daniel H. (2013) Mice lacking the intestinal peptide transporter display reduced energy intake and a subtle maldigestion/malabsorption that protects them from diet-induced obesity. Am. J. Physiol. Gastrointest. Liver Physiol. 304(10): G897-G907.

Krapivner S., Iglesias M.J., Silveira A., Tegner J., Bjorkegren J., Hamsten A., van't Hooft F.M. (2010) DGAT1 Participates in the effect of HNF4A on hepatic secretion of triglyceride-rich lipoproteins. Arterioscler. Thromb. Vasc. Biol. 30(5): 962-967.

Kwon E.J., You Y.-A., Park B., Ha E.H., Kim H.S., Park H., Kim Y.J. (2018) Association between the DNA methylations of POMC, MC4R, and HNF4A and metabolic profiles in the blood of children aged $7-9$ years. BMC Pediatr. 18(1): 121.

Kwon E.J., Lee H.A., You Y.-A., Yoo J.Y., Park H., Park E.A., Ha E.H., Kim Y.J. (2019) MC4R and HNF4a promoter methylation at birth contribute to triglyceride levels in childhood. A prospective cohort study. Medicine 98(28): e16424.

Lai C.-H., Chou C.-Y., Ch'ang L.-Y., Liu C.-S., Lin W. (2000) Identification of novel human genes evolutionarily conserved in Caenorhabditis elegans by comparative proteomics. Genome Res. 10(5): 703-713.

Laplante M., Sabatini D.M. (2012) mTOR signaling in growth control and disease. Cell 149(2): 274-293.

Larsen P.J., Tennagels N. (2014) On ceramides, other sphingolipids and impaired glucose homeostasis. Mol. Metabol. 3(3): 252-260.

Leahy J.L., Cooper H.E., Deal D.A., Weir G.C. (1986) Chronic hyperglycemia is associated with impaired glucose influence on insulin secretion. A study in normal rats using chronic in vivo glucose infusions. J. Clin. Invest. 77(3): 908-915.

Lee H., Bae S., Yoon Y. (2013) The anti-adipogenic effects of (-)epigallocatechin gallate are dependent on the $W N T / \beta$ catenin pathway. J. Nutr. Bioch. 24(7): 1232-1240.

Lee P.L., Tang Y., Li H., Guertin D.A. (2016) Raptor /mTORC1 loss in adipocytes causes progressive lipodystrophy and fatty liver disease. Mol. Metab. 5(6): 422-432.

Lee S.S., Kennedy S., Tolonen A.C., Ruvkun G. (2003) DAF-16 target genes that control C. elegans life-span and metabolism. Science 300(5619): 644-647.

Lemieux G.A, Liu J., Mayer N., Bainton R.J., Ashrafi K., Werb Z. (2011) $A$ whole-organism screen identifies new regulators of fat storage. Nat. Chem. Biol. 7(4): 206-213.
Ley R.E., Turnbaugh P.J., Klein S., Gordon J.I. (2006) Human gut microbes associated with obesity. Nature 444(7122): 1022-1023.

Li Y., Ding W., Li C., Liu Y. (2020) HLH-11 modulates lipid metabolism in response to nutrient availability. Nature Commun. 11(1): 5959.

Liang B., Ferguson K., Kadyk L., Watts J.L. (2010) The role of nuclear receptor NHR-64 in fat storage regulation in Caenorhabditis elegans. PLoS One 5(3): e9869.

Lin C., Lin Y., Chen Y., Xu J., Li J., Cao Y., Su Z., Chen Y. (2019) Effects of Momordica saponins extract on alleviating fat accumulation in Caenorhabditis elegans. Food Funct. 10(6): 3237-3251.

Lin Y., Bao B., Yin H., Wang X., Feng A., Zhao L., Nie X., Yang N., Shi G.-P., Liu J. (2019a) Peripheral cathepsin L inhibition induces fat loss in C. elegans and mice through promoting central serotonin synthesis. BMC Biol. 17(1): 93.

Lin Y., Yang N., Bao B., Wang L., Chen J., Liu J. (2020) Luteolin reduces fat storage in Caenorhabditis elegans by promoting the central serotonin pathway. Food Funct. 11(1): 730-740.

Lindhurst M.J., Parker V.E.R., Payne F., Sapp J.C., Rudge S., Harris J., Witkowski A.M., Zhang Q., Groeneveld M.P., Scott C.E. et al. (2012) Mosaic overgrowth with fibroadipose hyperplasia is caused by somatic activating mutations in PIK3CA. Nature Gen. 44(8): 928-933.

Lipert B., Wegrzyn P., Sell H., Eckel J., Winiarski M., Budzynski A., Matlok M., Kotlinowski J., Ramage L., Malecki M. et al. (2014) Monocyte chemoattractant protein-induced protein 1 impairs adipogenesis in 3T3-L1 cells. Biochim. Biophys. Acta, 1843(4): 780-788.

Liu Z., Li X., Ge Q., Ding M., Huang X. (2014) A lipid dropletassociated GFP reporter-based screen identifies new fat storage regulators in C. elegans. J. Genet. Genom. 41(5): 305-313.

Losko M., Dolicka D., Pydyn N., Jankowska U., Kedracka-Krok S., Kulecka M., Paziewska A., Mikula M., Major P., Winiarski M. et al. (2020) Integrative genomics reveal a role for MCPIP1 in adipogenesis and adipocyte metabolism. Cell. Mol. Life Sci. 77: 4899-4919.

Lundgren M., Svensson M., Lindmark S., Renström F., Ruge T., Eriksson J.W. (2007) Fat cell enlargement is an independent marker of insulin resistance and hyperleptinaemia. Diabetologia 50(3): 625-633.

Ma D.K., Li Z., Lu A.Y., Sun F., Chen S., Rothe M., Menzel R., Sun F., Horvitz H.R. (2015) Acyl-CoA dehydrogenase drives heat adaptation by sequestering fatty acids. Cell 161(5): 1152-1163.

Macedo F., Martins G.L., Luevano-Martinez L.A., Viana G.M., Riske K.A., Inague A., Yoshinaga M.Y., Aguilaniu H., Miyamoto S., Glezer I., da Cunha F.M. (2019) Lipase-like 5 enzyme controls mitochondrial activity in response to starvation in Caenorhabditis elegans. Biochim. Biophys. Acta: Mol. Cell. Biol. Lipids 1865(2): 158539.

MacNeil L.T., Watson E., Arda H.E., Zhu L.J., Walhout A.J.M. (2013) Diet-induced developmental acceleration independent of TOR and insulin in C. elegans. Cell 153(1): 240-252. 
Mak H.Y. (2011) Lipid droplets as fat storage organelles in Caenorhabditis elegans. J. Lipid Res. 53(1): 28-33.

Mao R., Yang R., Chen X., Harhaj E.W., Wang X., Fan Y. (2017) Regnase-1, a rapid response ribonuclease regulating inflammation and stress responses. Cell. Mol. Immun. 14(5): 412-422.

Mar-Heyming R., Miyazaki M., Weissglas-Volkov D., Kolaitis N.A., Sadaat N., Plaisier C., Pajukanta P., Cantor R.M., de Bruin T.W.A., Ntambi J.M., Lusis A.J. (2008) Association of stearoyl-CoA desaturase 1 activity with familial combined hyperlipidemia. Arterioscler. Thromb. Vasc. Biol. 28(6): 1193-1199.

Marette A., Dimitrakoudis D., Shi Q., Rodgers C.D., Klip A., Vranic M. (1999) Glucose rapidly decreases plasma membrane GLUT4 content in rat skeletal muscle. Endocrine 10(1): 13-18.

Marmol P., Krapacher F.F., Ibanez C. (2020) Control of brown adipose tissue adaptation to nutrient stress by the activin receptor ALK7. eLife 9: e54721.

Maruvada P., Leone V., Kaplan L.M., Chang E.B. (2017) The human microbiome and obesity: moving beyond associations. Cell. Host. Microbe. 22(5): 589-599.

McElwee J.J., Schuster E., Blanc E., Thornton J., Gems D. (2006) Diapause-associated metabolic traits reiterated in long-lived daf-2 mutants in the nematode Caenorhabditis elegans. Mechan. Ageing Develop. 127(5): 458-472.

McKay R.M., McKay J.P., Avery L., Graff J.M. (2003) C. elegans: a model for exploring the genetics of fat storage. Dev. Cell. 4(1): 131-142.

Meierhofer D., Halbach M., Şen N.E., Gispert S., Auburger G. (2016) Ataxin-2 (Atxn2)-knock-out mice show branched chain amino acids and fatty acids pathway alterations. Mol. Cell. Proteom. 15(5): 1728-1739.

Miyazaki M., Kim Y.-C., Gray-Keller M.P., Attie A.D., Ntambi J.M. (2000) The biosynthesis of hepatic cholesterol esters and triglycerides is impaired in mice with a disruption of the gene for stearoyl-CoA desaturase 1. J. Biol. Chem. 275(9): 30132-30138.

Moreno-Arriola E., El Hafidi M., Ortega-Cuéllar D., Carvajal K. (2016) AMP-activated protein kinase regulates oxidative metabolism in Caenorhabditis elegans through the NHR-49 and MDT-15 transcriptional regulators. PLoS One 11(1): $\mathrm{e} 0148089$.

Mukhopadhyay A., Deplancke B., Walhout A.J.M., Tissenbaum H.A. (2005) C. elegans tubby regulates life span and fat storage by two independent mechanisms. Cell Metabol. 2(1): $35-42$

Mullaney B.C., Ashrafi K. (2009) C. elegans fat storage and metabolic regulation. Biochim. Biophys. Acta: Mol. Cell Biol. Lipids 1791(6): 474-478.

Murase T., Misawa K., Haramizu S., Hase T. (2009) Catechininduced activation of the LKB1/AMP-activated protein kinase pathway. Bioch. Pharmacol. 78(1): 78-84.

Murphy C.T., McCarroll S.A., Bargmann C.I., Fraser A., Kamath R.S., Ahringer J., Li H., Kenyon C. (2003) Genes that act downstream of DAF-16 to influence the lifespan of Caenorhabditis elegans. Nature 424(6946): 277-283.
Murray P., Hayward S.A.L., Govan G.G., Gracey Y.A., Cossins A.R. (2007) An explicit test of the phospholipid saturation hypothesis of acquired cold tolerance in Caenorhabditis elegans. Proc. Natl Acad. Sci. USA 104(13): 5489-5494.

Muzik O., Mangner T.J., Leonard W.R., Kumar A., Janisse J., Granneman J.G. (2013) 150 PET measurement of blood flow and oxygen consumption in cold-activated human brown fat. J. Nucl. Med. 54(4): 523-531.

Navarro-Herrera D., Aranaz P., Eder-Azanza L., Zabala M., Hurtado C., Hualde A.R., Martinez J.A., Gonzalez-Navarro C.J., Vizmanos J.L. (2018a) Dihomo-gamma-linolenic acid induces fat loss in $C$. elegans in an omega-3-independent manner by promoting peroxisomal fatty acid $\beta$-oxidation. Food Funct. 9(3): 1621-1637.

Navarro-Herrera D., Aranaz P., Eder-Azanza L., Zabala M., Romo-Hualde A., Hurtado, C., Diego C., López-Yoldi M., Martínez J.A., González-Navarro C.J., Vizmanos J.L. (2018) Borago officinalis seed oil (BSO), a natural source of omega- 6 fatty acids, attenuates fat accumulation by activating peroxisomal beta-oxidation both in $C$. elegans and in diet-induced obese rats. Food Func. 9(8): 4340-4351.

Nehrke K. (2003) A reduction in intestinal cell pHi due to loss of the Caenorhabditis elegans $\mathrm{Na}+/ \mathrm{H}+$ exchanger $\mathrm{NHX}-2$ increases life span. J. Biol. Chem. 278(45): 44657-44666.

Nies V.J.M., Struik D., Wolfs M.G.M., Rensen S.S., Szalowska E., Unmehopa U.A., Fluiter K., van der Meer T.P., Hajmousa G., Buurman W.A. et al. (2017) TUB gene expression in hypothalamus and adipose tissue and its association with obesity in humans. Int. J. Obesity 42(3): 376-383.

Niswender K.D., Schwartz M.W. (2003) Insulin and leptin revisited: adiposity signals with overlapping physiological and intracellular signaling capabilities. Front. Neuroendocrinol. 24(1): 1-10.

Noben-Trauth K., Naggert J.K., North M.A., Nishina P.M. (1996) A candidate gene for the mouse mutation tubby. Nature 380(6574): 534-538.

Noble T., Stieglitz J., Srinivasan S. (2013) An integrated serotonin and octopamine neuronal circuit directs the release of an endocrine signal to control $C$. elegans body fat. Cell Metab. 18(5): 672-684.

Nomura T., Horikawa M., Shimamura S., Hashimoto T., Sakamoto K. (2010) Fat accumulation in Caenorhabditis elegans is mediated by SREBP homolog SBP-1. Genes Nutr. 5(1): 17-27.

Nomura S., Ichinose T., Jinde M., Kawashima Y., Tachiyashiki K., Imaizumi K. (2008) Tea catechins enhance the mRNA expression of uncoupling protein 1 in rat brown adipose tissue. J. Nutr. Bioch. 19(12): 840-847.

Nonogaki K., Strack A.M., Dallman M.F., Tecott L.H. (1998) Leptin-independent hyperphagia and type 2 diabetes in mice with a mutated serotonin 5-HT2C receptor gene. Nature Med. 4(10): 1152-1156.

Ntambi J.M., Miyazaki M., Stoehr J.P., Lan H., Kendziorski C.M., Yandell B.S., Song Y., Cohen P., Friedman J.M., Attie A.D. (2002) Loss of stearoyl-CoA desaturase-1 function protects mice against adiposity. Proc. Natl Acad. Sci. USA 99(17): 11482-11486. 
Ong K.W., Hsu A., Tan B.K.H. (2013) Anti-diabetic and antilipidemic effects of chlorogenic acid are mediated by ampk activation. Biochem. Pharmacol. 85(9): 1341-1351.

O'Rourke E.J., Soukas A.A., Carr C.E., Ruvkun G. (2009) C. elegans major fats are stored in vesicles distinct from lysosome-related organelles. Cell Metabol. 10(5): 430-435.

O'Rourke E.J., Ruvkun G.M. (2013) MXL-3 and HLH-30 transcriptionally link lipolysis and autophagy to nutrient availability. Nat. Cell Biol. 15(6): 668-676.

Ouellet V., Labbé S.M., Blondin D.P., Phoenix S., Guérin B., Haman F., Turcotte E.E., Richard D., Carpentier A.C., (2012) Brown adipose tissue oxidative metabolism contributes to energy expenditure during acute cold exposure in humans. J. Clin. Invest. 122(2): 545-552.

Pang G., Xie J., Chen Q., Hu Z. (2014) Energy intake, metabolic homeostasis, and human health. Food Sci. Human Wellness 3(3-4): 89-103.

Park D., Jones K.L., Lee H., Snutch T.P., Taubert S., Riddle D.L. (2012) Repression of a potassium channel by nuclear hormone receptor and TGF- $b$ signaling modulates insulin signaling in Caenorhabditis elegans. PLoS Genet. 8(2): e1002519.

Pathare P.P., Lin A., Bornfeldt K.E., Taubert S., Van Gilst M.R. (2012) Coordinate regulation of lipid metabolism by novel nuclear receptor partnerships. PLoS Genet. 8(4): e1002645.

Perez C.L., Van Gilst M.R. (2008) A 13C isotope labeling strategy reveals the influence of insulin signaling on lipogenesis in C. elegans. Cell Metabol. 8(3): 266-274.

Rani P.U., Kesavan R., Ganugula R.T.A., Kumar P.U., Reddy G.B., Dixit M. (2013) Ellagic acid inhibits PDGF-BB-induced vascular smooth muscle cell proliferation and prevents atheroma formation in streptozotocin-induced diabetic rats. J. Nutr. Biochem. 24(11): 1830-1839.

Rankinen T., Zuberi A., Chagnon Y.C., Weisnagel S.J., Argyropoulos G., Walts B., Perusse L., Bouchard C. (2006) The human obesity gene map: the 2005 update. Obesity 14(4): 529-644.

Reinke S.N., Hu X., Sykes B.D., Lemire B.D. (2010) Caenorhabditis elegans diet significantly affects metabolic profile, mitochondrial DNA levels, lifespan and brood size. Mol. Gen. Metabol. 100(3): 274-282.

Rinia H.A., Burger K.N.J., Bonn M., Muller M. (2008) Quantitative label-free imaging of lipid composition and packing of individual cellular lipid droplets using multiplex CARS microscopy. Biophys. J. 95(10): 4908 - 4914.

Röder P.V., Wu B., Liu Y., Han W. (2016) Pancreatic regulation of glucose homeostasis. Exp. Mol. Med. 48(3): e219.

Sahly I., Gogat K., Kobetz A., Marchant D., Menasche M., Castel M.-N., Revah F., Dufier J.-L., Guerre-Millo M., Abitbol M.M. (1998) Prominent neuronal-specific tub gene expression in cellular targets of tubby mice mutation. Human Mol. Genet. 7(9): 1437-1447.

Saif-Ali R., Harun R., Kamaruddin N.A., Al-Jassabi S., Ngah W.Z.W. (2011) Association of hepatocyte nuclear factor 4 alpha polymorphisms with type 2 diabetes with or without metabolic syndrome in Malaysia. Bioch. Gen. 50(3-4): 298-308.

Samuel B.S., Rowedder H., Braendle C., Félix M.-A., Ruvkun G. (2016) Caenorhabditis elegans responses to bacteria from its natural habitats. Proc. Natl Acad. Sci. USA 113(27): E3941-E3949.

Samuels Y., Wang Z., Bardelli A., Silliman N., Ptak J., Szabo S., Yan H., Gazdar A., Powell S.M., Riggins G.J. et al. (2004) High frequency of mutations of the PIK3CA gene in human cancers. Science 304(5670): 554-554.

Sanjabi B., Dashty M., Özcan B., Akbarkhanzadeh V., Rahimi M., Vinciguerra M., van Rooij F., Al-Lahham S., Sheedfar F., van Kooten T.G. et al. (2015) Lipid droplets hypertrophy: a crucial determining factor in insulin regulation by adipocytes. Sci. Rep. 5(1).

Savory F.R., Sait S.M., Hope I.A. (2011) DAF-16 and D9 desaturase genes promote cold tolerance in long-lived Caenorhabditis elegans age-1 mutants. PLoS One 6(9): e24550.

Schlegel A., Stainier D.Y.R., (2007) Lessons from lower organisms: what worms, flies, and zebrafish can teach us about human energy metabolism. PLoS Genet. 3(11): 199.

Schooneman G.M., Vaz F.M., Houten S.M., Soeters M.R. (2013) Acylcarnitines reflecting or inflicting insulin resistance? Diabetes 62(1): 1-8.

Scott T.A., Quintaneiro L.M., Norvaisas P., Lui P.P., Wilson M.P., Leung K.-Y., Herrera-Dominguez L., Sudiwala S., Pessia A., Clayton P.T. et al. (2017) Host-microbe co-metabolism dictates cancer drug efficacy in $C$. elegans. Cell 169(3): 442-456.

Shen C.-Y., Wan L., Wang T.-X., Jiang J.-G. (2019) Citrus aurantium L. var. amara Engl. inhibited lipid accumulation in 3T3-L1 cells and Caenorhabditis elegans and prevented obesity in high-fat diet-fed mice. Pharmacol. Res. 147: 104347.

Shepherd P.R., Kahn B.B. (1999) Glucose transporters and insulin action- implications for insulin resistance and diabetes mellitus. New Engl. J. Med. 341(4): 248-257.

Shi X., Li J., Zou X., Greggain J., Rodkaer S.V., Færgeman N.J., Liang B., Watts J.L. (2013) Regulation of lipid droplet size and phospholipid composition by stearoyl-CoA desaturase. J. Lipid Res. 54(9): 2504-2514.

Shiri-Sverdlov R., Custers A., van Vliet-Ostaptchouk J.V., van Gorp P.J.J., Lindsey P.J., van Tilburg J.H.O., Zhernakova S., Feskens E.J.M., van der A.D.L., Dollé M.E.T. et al. (2006) Identification of TUB as a novel candidate gene influencing body weight in humans. Diabetes 55(2): 385-389.

Softic S., Boucher J., Solheim M.H., Fujisaka S., Haering M.F., Homan E.P., Winnay J., Perez-Atayde A.R., Kahn C.R. (2016) Lipodystrophy due to adipose tissue-specific insulin receptor knockout results in progressive NAFLD. Diabetes 65(8): 2187-2200.

Son J.H., Baker H., Park D.H., Joh T.H. (1994) Drastic and selective hyperinnervation of central serotonergic neurons in a lethal neurodevelopmental mouse mutant, Anorexia (anx). Mol. Brain Res. 25(1-2): 129-134. 
Sonnhammer E.L.L., Durbin R. (1997) Analysis of protein domain families in Caenorhabditis elegans. Genomics 46(2): 200-216.

Soukas A.A., Kane E.A., Carr C.E., Melo J.A., Ruvkun G. (2009) Rictor/TORC2 regulates fat metabolism, feeding, growth, and life span in Caenorhabditis elegans. Genes Dev. 23(4): 496- 511.

Spanier B., Lasch K., Marsch S., Benner J., Liao W., Hu H., Kienberger H., Eisenreich W., Daniel H. (2009) How the intestinal peptide transporter PEPT-1 contributes to an obesity phenotype in Caenorhabditis elegans. PLoS One 4(7): 6279.

Srinivasan S., Sadegh L., Elle I. C., Christensen A.G.L., Faergeman N.J., Ashrafi K. (2008) Serotonin regulates $C$. elegans fat and feeding through independent molecular mechanisms. Cell Metab. 7(6): 533-544.

Srinivasan S. (2015) Regulation of body fat in Caenorhabditis elegans. Annu. Rev. Physiol. 77(1): 161-178.

Stanislawski M.A., Dabelea D., Lange L.A., Wagner B.D., Lozupone C.A. (2019) Gut microbiota phenotypes of obesity. Biofilms Microbiom. 5(1): 18.

Stern J.S., Hollander N., Batchelor B.R., Cohn C.K., Hirsch J. (1972) Adipose-cell size and immunoreactive insulin levels in obese and normal-weight adults. Lancet 300(7784): 948-951.

Stoffel M., Duncan S.A. (1997) The maturity-onset diabetes of the young (MODY1) transcription factor HNF4a regulates expression of genes required for glucose transport and metabolism. Proc. Natl Acad. Sci. USA 94(24): 13209-13214.

Stiernagle T. (2006) Maintenance of $C$. elegans. The $C$. elegans Research Community, WormBook, doi/10.1895/ wormbook.1.101.1, http://www.wormbook.org.

Stubdal H., Lynch C.A., Moriarty A., Fang Q., Chickering T., Deeds J.D., Fairchild-Huntress V., Charlat O., Dunmore J.H., Kleyn P. et al. (2000) Targeted deletion of the tub mouse obesity gene reveals that tubby is a loss-of-function mutation. Mol. Cell Biol. 20(3): 878-882.

Stuhr N.L., Curran S.P. (2020) Bacterial diets differentially alter lifespan and healthspan trajectories in C. elegans. Commun. Biol. 3(1): 653.

Sulston J.E., Horvitz H.R. (1977) Post-embryonic cell lineages of the nematode, Caenorhabditis elegans. Develop. Biol. 56(1): 110-156.

Sulston J.E., Schierenberg E., White J.G., Thomson J.N. (1983) The embryonic cell lineage of the nematode Caenorhabditis elegans. Develop. Biol. 100(1): 64-119.

Sun Q., Yue Y., Shen P., Yang J.J., Par Y. (2016) Cranberry product decreases fat accumulation in Caenorhabditis elegans. J. Med. Food 19(4): 427-433.

Suppli M.P., Rigbolt K.T.G., Veidal S.S., Heebøll S., Eriksen P.L., Demant M., Bagger J.I., Nielsen J.C., Oró D., Thrane S.W. et al. (2019) Hepatic transcriptome signatures in patients with varying degrees of nonalcoholic fatty liver disease compared with healthy normal-weight individuals. Am. J. Physiol. Gastrointest. Liver Physiol. 316(4): G462-G472.
Svensk E., Ståhlman M., Andersson C.-H., Johansson M., Borén J., Pilon M. (2013) PAQR-2 regulates fatty acid desaturation during cold adaptation in C. elegans. PLoS Genet. 9(9): e1003801.

Svensk E., Devkota R., Ståhlman M., Ranji P., Rauthan M., Magnusson F., Hammarsten S., Johansson M., Borén J., Pilon M. (2016) Caenorhabditis elegans PAQR-2 and IGLR2 protect against glucose toxicity by modulating membrane lipid composition. PLoS Genet. 12(4): e1005982.

Svensson E., Olsen L., Mörck C., Brackmann C., Enejder A., Faergeman N.J., Pilon M. (2011) The adiponectin receptor homologs in C. elegans promote energy utilization and homeostasis. PLoS One 6(6): e21343.

Sze J.Y., Victor M., Loer C., Shi Y., Ruvkun G. (2000) Food and metabolic signaling defects in a Caenorhabditis elegans serotonin-synthesis mutant. Nature 403(6769): 560-564.

Tabrizi R., Tamtaji O.R., Lankarani K.B., Akbari M., Dadgostar E., Dabbaghmanesh M.H., Kolahdooz F., Shamshirian A., Momen-Heravi M., Asemi Z. (2020) The effects of resveratrol intake on weight loss: a systematic review and metaanalysis of randomized controlled trials. Crit. Rev. Food Sci. Nutr. 60(3): 375-390.

Takeuchi Y., Yahagi N., Aita Y., Murayama Y., Sawada Y., Piao X., Toya N., Oya Y., Shikama A., Takarada A. et al. (2016) KLF15 enables rapid switching between lipogenesis and gluconeogenesis during fasting. Cell Rep. 16(9): 2373-2386.

Tanaka T., Ikita K., Ashida T., Motoyama Y., Yamaguchi Y., Satouchi K. (1996) Effects of growth temperature on the fatty acid composition of the free-living nematode Caenorhabditis elegans. Lipids 31(11): 1173-1178.

Taubert S., Van Gilst M.R., Hansen M., Yamamoto K.R. (2006) A mediator subunit, MDT-15, integrates regulation of fatty acid metabolism by NHR-49-dependent and -independent pathways in C. elegans. Genes Develop. 20(9): 1137-1149.

Tauchi-Sato K., Ozeki S., Houjou T., Taguchi R., Fujimoto T. (2002) The surface of lipid droplets is a phospholipid monolayer with a unique fatty acid composition. J. Biol. Chem. 277(46): 44507-44512.

Tecott L.H., Sun L.M., Akana S.F., Strack A.M., Lowenstein D.H., Dallman M.F., Julius D. (1995) Eating disorder and epilepsy in mice lacking 5-HT2C serotonin receptors. Nature 374(6522): 542-546.

Thamotharan M., Bawani S.Z., Zhou X., Adibi S.A. (1999) Hormonal regulation of oligopeptide transporter pept-1 in a human intestinal cell line. Am. J. Physiol. 276(4): C821-C826.

The $C$. elegans Sequencing Consortium (1998) Genome sequence of the nematode $C$. elegans: a platform for investigating biology. Science 282(5396): 2012-2018.

Tilman D., Clark M. (2014) Global diets link environmental sustainability and human health. Nature 515(7528): 518-522.

Townsend K.L., Tseng Y.-H. (2014) Brown fat fuel utilization and thermogenesis. Trends Endocrinol. Metabol. 25(4): $168-177$. 
Trayhurn P. (2007) Adipocyte biology. Obes. Rev. 8(s1): 41-44. Trepanowski J.F., Canale R.E., Marshall K.E., Kabir M.M., Bloomer R.J. (2011) Impact of caloric and dietary restriction regimens on markers of health and longevity in humans and animals: a summary of available findings. Nutr. J. 10(1): 107.

Turnbaugh P.J., Ley R.E., Mahowald M.A., Magrini V., Mardis E.R., Gordon J.I. (2006) An obesity-associated gut microbiome with increased capacity for energy harvest. Nature 444(7122): 1027-1031.

Turnbaugh P.J., Ridaura V.K., Faith J.J., Rey F.E., Knight R., Gordon J.I. (2009) The effect of diet on the human gut microbiome: a metagenomic analysis in humanized gnotobiotic mice. Sci. Transl. Med. 1(6): 6ra14.

Van Gilst M.R., Hadjivassiliou H., Yamamoto K.R. (2005) $A$ Caenorhabditis elegans nutrient response system partially dependent on nuclear receptor NHR-49. Proc. Natl Acad. Sci. USA 102(38): 13496-13501.

Van Vliet-Ostaptchouk J.V., Onland-Moret N.C., Shiri-Sverdlov R., van Gorp P.J.J., Custers A., Peeters P.H.M., Wijmenga C., Hofker M.H., van der Schouw Y.T. (2008) Polymorphisms of the TUB gene are associated with body composition and eating behavior in middle-aged women. PLoS One 3(1): e1405.

Vinayagam R., Jayachandran M., Xu B. (2015) Antidiabetic effects of simple phenolic acids: a comprehensive review. Phytother. Res. 30(2): 184-199.

Vinknes K.J, Elshorbagy A.K., Nurk E., Drevon C.A., Gjesdal C.G., Tell G.S., Nygard O., Vollset S.E., Refsum H., (2013) Plasma stearoyl-CoA desaturase indices: association with lifestyle, diet, and body composition. Obesity 21(3): E294-E302.

Vrablik T.L., Petyuk V.A., Larson E.M., Smith R.D., Watts J.L. (2015) Lipidomic and proteomic analysis of Caenorhabditis elegans lipid droplets and identification of ACS-4 as a lipid droplet-associated protein. Biochim. Biophys. Acta: Mol. Cell Biol. Lipids 1851(10): 1337-1345.

Walker A.W., Ince J., Duncan S.H., Webster L.M., Holtrop G., Ze X., Brown D., Stares M.D., Scott P., Bergerat A., Louis P., McIntosh F., Johnstone A.M., Lobley G.E., Parkhill J., Flint H.J. (2011) Dominant and diet-responsive groups of bacteria within the human colonic microbiota. ISME J. 5: $220-230$.

Wallis J.G., Watts J.L., Browse J. (2002) Polyunsaturated fatty acid synthesis: what will they think of next? Trends Bioch. Sci. 27(9): 467-473.

Wang J., Yu L., Schmidt R.E., Su C., Huang X., Gould K., Cao G. (2005) Characterization of HSCD5, a novel human stearoyl-CoA desaturase unique to primates. Biochem. Biophys. Res. Commun. 332(3): 735-742.

Wang X., Zhang L., Zhang L., Wang W., Wei S., Wang J., Che H., Zhang Y. (2020) Effects of excess sugars and lipids on the growth and development of Caenorhabditis elegans. Genes Nutr. 15(1).

Warensjo E., Ingelsson E., Lundmark P., Lannfelt L., Syvanen A.-C., Vessby B., Riserus U. (2007) Polymorphisms in the
SCD1 gene: associations with body fat distribution and insulin sensitivity. Obesity 15(7): 1732-1740.

Watanabe H., Nakano T., Saito R., Akasaka D., Saito K., Ogasawara H., Minashima T., Miyazawa K., Kanaya T., Takakura I. et al. (2016) Serotonin improves high fat diet induced obesity in mice. PLoS One 11(1): e0147143.

Watanabe K., Terada K., Sato J. (2003) Intestinal absorption of cephalexin in diabetes mellitus model rats. Eur. J. Pharm. Sci. 19(2-3): 91-98.

Watts J.L., Browse J. (2002) Genetic dissection of polyunsaturated fatty acid synthesis in Caenorhabditis elegans. Proc. Natl Acad. Sci. USA 99(9): 5854-5859.

Watts J.L., Ristow M. (2017) Lipid and carbohydrate metabolism in Caenorhabditis elegans. Genetics 207: 413-446.

Wei M., Brandhorst S., Shelehchi M., Mirzaei H., Cheng C.W., Budniak J., Groshen S., Mack W.J., Guen E., Biase S.D. et al. (2017) Fasting-mimicking diet and markers/risk factors for aging, diabetes, cancer, and cardiovascular disease. Sci. Transl. Med. 9(377): eaai8700.

Welton S., Minty R., O’Driscoll T., Willms H., Poirier D., Madden S., Kelly L. (2020) Intermittent fasting and weight loss. Can. Fam. Physician. 66(2): 117-125.

White B. (2009) Dietary fatty acids. Am. Fam. Physician. 80(4): 345-350.

Wilfling F., Wang H., Haas J.T., Krahmer N., Gould T.J., Uchida A., Cheng J.-X., Graham M., Christiano R., Frohlich F. et al. (2013) Triacylglycerol synthesis enzymes mediate lipid droplet growth by relocalizing from the ER to lipid droplets. Develop. Cell 24(4): 384-399.

Willett W.C., Dietz W.H., Colditz G.A. (1999) Guidelines for healthy weight. New Engl. J. Med. 341(6): 427-434.

Woods A., Williams J.R., Muckett P.J., Mayer F.V., Liljevald M., Bohlooly Y.M., Carling D. (2017) Liver-specific activation of AMPK prevents steatosis on a high-fructose diet. Cell Rep. 18(13): 3043-3051.

World Health Organization (1998) Obesity: preventing and managing the global epidemic: report of a WHO Consultation on Obesity. World Health Organization, Geneva: 276.

Xu J., Peng W., Sun Y., Wang X., Xu Y., Li X., Gao G., Rao Z. (2012) Structural study of MCPIP1 N-terminal conserved domain reveals a PIN-like RNase. Nucl. Acids Res. 40(14): 6957-6965.

Xu N., Zhang S.O., Cole R.A., McKinney S.A., Guo F., Haas J.T., Bobba S., Farese R.V.Jr, Mak H.Y. (2012a) The FATP1$D G A T 2$ complex facilitates lipid droplet expansion at the ER-lipid droplet interface. J. Cell Biol. 198(5): 895-911.

Xu N., Zhang L., Dong J., Zhang X., Chen Y.-G., Bao B., Liu J. (2014) Low-dose diet supplement of a natural flavonoid, luteolin, ameliorates diet-induced obesity and insulin resistance in mice. Mol. Nutr. Food Res. 58(6): 1258-1268.

Xu Q., Mariman E.C.M., Goossens G.H., Blaak E.E., Jockenc J.W.E. (2020) Cathepsin gene expression in abdominal subcutaneous adipose tissue of obese/ overweight humans. Adipocyte 9(1): 246-252.

Yabut J.M., Crane J.D., Green A.E., Keating D.J., Khan W.I., Steinberg G.R. (2019) Emerging roles for serotonin in 
regulating metabolism: new implications for an ancient molecule. Endocrine Rev. 40(4): 1092-1107.

Yamagata K., Furuta H., Oda N., Kaisaki P.J., Menzel S., Cox N.J., Fajans S.S., Signorini S., Stoffel M., Bell G.I. (1996) Mutations in the hepatocyte nuclear factor-4a gene in maturity-onset diabetes of the young (MODY1). Nature 384(6608): 458-460.

Yang F., Vought B.W., Satterlee J.S., Walker A.K., Sun Z.Y.J., Watts J.L., DeBeaumont R., Saito R.M., Hyberts S.G., Yang S. et al. (2006) An ARC/Mediator subunit required for SREBP control of cholesterol and lipid homeostasis. Nature 442(7103): 700-704.

Yang M., Zhang Y., Pan J., Sun J., Liu J., Libby P., Sukhova G.K., Doria A., Katunuma N., Peroni O.D. et al. (2007) Cathepsin L activity controls adipogenesis and glucose tolerance. Nature Cell Biol. 9(8): 970-977.

Yang M., Sun J., Zhang T., Liu J., Zhang J., Shi M.A., Darakhshan F., Guerre-Millo M., Clement K., Gelb B.D., Dolgnov G., Shi G.-P. (2008) Deficiency and inhibition of cathepsin $K$ reduce body weight gain and increase glucose metabolism in mice. Arterioscler. Thromb. Vasc. Biol. 28(12): 2202-2208.

Ye L., Wu J., Cohen P., Kazak L., Khandekar M.J., Jedrychowski M.P., Zeng X., Gygi S.P., Spiegelman B.M. (2013) Fat cells directly sense temperature to activate thermogenesis. Proc. Natl Acad. Sci. USA 110(30): 12480-12485.

Yoneshiro T., Aita S., Matsushita M., Kayahara T., Kameya T., Kawai Y., Iwanaga T., Saito M. (2013) Recruited brown adipose tissue as an antiobesity agent in humans. J. Clin. Invest. 123(8): 3404-3408.

Yoon S.A., Kang S.I., Shin H.S., Kang S.-W., Kim J.-H., Ko H.C., Kim S.-J. (2013) p-Coumaric acid modulates glucose and lipid metabolism via AMP-activated protein kinase in L6 skeletal muscle cells. Biochem. Biophys. Res. Commun. 432(4): 553-557.

You Y., Kim J., Raizen D.M., Avery L. (2008) Insulin, cGMP, and TGF $\beta$ signals regulate food intake and quiescence in $C$. elegans: a model for satiety. Cell Metabol. 7(3): 249-257.

Younce C.W., Azfer A., Kolattukudy P.E. (2009) MCP-1 (monocyte chemotactic protein-1)-induced protein, a recently identified zinc finger protein, induces adipogenesis in 3T3-L1 pre-adipocytes without peroxisome proliferator-activated receptor gamma. J. Biol. Chem. 284(40): 27620-27628.

Younce C., Kolattukudy P.E. (2012) MCP-1 induced protein promotes adipogenesis via oxidative stress, endoplasmic reticulum stress and autophagy. Cell. Physiol. Biochem. 30(2): 307-320.

Young J.B., Saville E., Rothwell N.J., Stock M.J., Landsberg L. (1982) Effect of diet and cold exposure on norepinephrine turnover in brown adipose tissue of the rat. J. Clin. Invest. 69(5): 1061-1071.

Yue Y., Shen P., Xu Y., Park Y. (2018) p-Coumaric acid improves oxidative and osmosis stress responses in Caenorhabditis elegans. J. Sci. Food Agric. 99(3): 1190-1197.

Zaarur N., Desevin K., Mackenzie J., Lord A., Grishok A., Kandror K.V. (2019) ATGL-1 mediates the effect of dietary restriction and the insulin/IGF-1 signaling pathway on longevity in C. elegans. Mol. Metab. 27: 75-82.

Zhang J., Bakheet R., Parhar R.S., Huang C.-H., Hussain M.M., Pan X., Siddiqui S.S., Hashmi S. (2011) Regulation of fat storage and reproduction by Krüppel-Like Transcription Factor KLF3 and fat-associated genes in Caenorhabditis elegans. J. Mol. Biol. 411(3): 537-553.

Zhang P., Na H., Liu Z., Zhang S., Xue P., Chen Y., Pu J., Peng G., Huang X., Yang F. et al. (2012) Proteomic study and marker protein identification of Caenorhabditis elegans lipid droplets. Mol. Cell. Proteom. 11(8): 317-328.

Zhang P., Judy M., Lee S.-J., Kenyon C. (2013) Direct and indirect gene regulation by a life-extending FOXO protein in C. elegans: Roles for GATA factors and lipid gene regulators. Cell Metabol. 17(1): 85-100.

Zhang S.O., Box A.C., Xu N., Men J.L., Yu J., Guo F., Trimble R., Mak H.Y. (2010) Genetic and dietary regulation of lipid droplet expansion in Caenorhabditis elegans. Proc. Natl Acad. Sci. USA 107(10): 4640-4645.

Zhang X., Zhang Q.X., Wang X., Zhang L., Qu W., Bao B., Liu C.-A., Liu J. (2016) Dietary luteolin activates browning and thermogenesis in mice through an AMPK/PGCl $\alpha$ pathwaymediated mechanism. Int. J. Obesity 40: 1841-1849.

Zhang Y., Viennois E., Zhang M., Xiao B., Han M. K., Walter L., Garg P., Merlin D. (2016a) PepT1 expression helps maintain intestinal homeostasis by mediating the differential expression of miRNAs along the crypt-villus axis. Sci. Rep. 6: 27119.

Zhao L., Zhang F., Ding X., Wu G., Lam Y. Y., Wang X., Fu H., Xue X., Lu C., Ma J. et al. (2018) Gut bacteria selectively promoted by dietary fibers alleviate type 2 diabetes. Science 359(6380): 1151-1156.

Zheng J., Enright F., Keenan M., Finley J., Zhou J., Ye J., Greenway F., Senevirathe R.N., Gissendanner C.R., Manaois X.R. et al. (2010) Resistant starch, fermented resistant starch, and short-chain fatty acids reduce intestinal fat deposition in Caenorhabditis elegans. J. Agric. Food Chem. 58(8): 4744-4748.

Ziętak M., Kovatcheva-Datchary P., Markiewicz L.H., Stahlman M., Kozak L.P., Backhed F. (2016) Altered microbiota contributes to reduced det-induced obesity upon cold exposure. Cell Metabol. 23(6): 1216-1223.

Zietak M., Kozak L.P. (2016) Bile acids induce uncoupling protein 1-dependent thermogenesis and stimulate energy expenditure at thermoneutrality in mice. Am. J. Physiol. Endocrin. Metabol. 310(5): E346-E354.

Zimmermann J., Obeng N., Yang W., Pees B., Petersen C., Waschina S., Kissoyan K.A., Aidley J., Hoeppner M.P., Bunk B. et al. (2020) The functional repertoire contained within the native microbiota of the model nematode Caenorhabditis elegans. ISME J. 14(1): 26-38. 